\title{
SYSTEMATICS OF THE GENUS HETEROTHERA INOUE (LEPIDOPTERA, GEOMETRIDAE:
}

\author{
LARENTIINAE)
}

\begin{abstract}
S.-W. Choi, 1998, Systematics of the genus Heterothera Inoue (Lepidoptera, Geometridae: Larentiinae). - Tijdschrift voor Entomologie 141: 19-47, figs. 1-57. [Issn 0040-7496]. Published 30 November 1998.

The genus Heterothera Inoue, occurring widely in the Palaearctic and in the high mountains of the Oriental region, is revised and twenty-three species are recognized. Nine species are described as new: Heterothera hoenei Choi sp. n., H. yunnanensis Choi sp. n., H. triangulata Choi sp. n., H. eclinosis Choi sp. n., H. stamineata Choi sp. n., H. obscurata Choi sp. n., H. distinctata Choi sp. n., H. mussooriensis Choi sp. n. and H. kurenzovi Choi, Viidalepp \& Vasjurin sp. n., and five new combinations are suggested: Heterothera tephroptilus (Fletcher) comb. n., H. serrataria (Prout) comb. n., H. etes (Prout) comb. n., H. comitabilis (Prout) comb. n. and H. undulata (Warren) comb. n. A key and illustrations of adults and genitalia are given. The monophyly of Heterothera and the species relationships are discussed. In addition, four poorly known taxa of Thera sensu Prout, T. cyphoschema Prout (= atrinotata Joannis syn. n.), T. exangulata Warren, and Pennithera distractata Sterneck comb. n., are redescribed and the taxonomy of these species is briefly discussed.

Correspondence: Sei-Woong Choi, Department of Entomology, American Museum of Natural History, Central Park West at 79th St., New York, NY 10024, USA. E-mail: choisw@amnh.org Key words. - Systematics; Geometridae; Larentiinae; Heterothera; Palaearctic; Oriental.
\end{abstract}

The genus Heterothera Inoue consists of mediumsized geometrid moths in the subfamily Larentiinae, which are widely spread in the Palaearctic and Oriental regions. The genus was erected by Inoue (1943) based on the following characters: the absence of uncus, long anal tube, stout and flat saccus, weakly sclerotized costa and a well developed sacculus. The monophyly of the genus Heterothera s.s. was first defined by Viidalepp (1980). He listed seven apomorphies for the genus: the bifid saccus, the absence of an uncus, the membranous ductus and corpus bursae without signum, the simple sterigma, the distinct sacculus, the presence of cornuti on the vesica, and the filiform male antenna. Two synapomorphies out of seven, the bifid saccus and the absence of uncus, were unique to Heterothera s.s. However, the character 'absence of uncus' was found to be incorrect.

Inoue (1982) proposed a new genus Viidaleppia for the species of Asaphodes sensu Viidalepp (1980). Later, he (Inoue 1986) described the characters of the genus Viidaleppia as: doubly bipectinated male antenna, strongly sclerotized costa and pointed apex of forewing, sclerotized and plate-like sacculus, well developed apical projection of the sacculus, numerous spin- ular cornuti, well developed sterigma, and a broad ductus bursae.

However, the genus Heterothera s.s. was found to be paraphyletic in relation to Viidaleppia and the latter was synonymized with Heterothera in a cladistic analysis of the Cidariini sensu Herbulot (Choi 1997; see 'Diagnosis and monophyly' for synapomorphies).

Since the works of Prout $(1914,1938,1941)$, the taxonomy of Thera s.l. has been considerably changed, due to the discovery of many new species and a different analytical approach (e.g. Viidalepp 1980, Choi 1997). As a result of the cladistic analysis, the genus Heterothera s.l. is characterized by several derived characters and, based on these, many undescribed species of the genus have been recognized, mainly from southwestern China and northern India. The purpose of the present study is to revise the species of Heterothera. While the taxonomy of several poorly known species of Thera s.l., such as $T$. exangulata, $T$. cyphoschema, T. atrinotata and T. distractata, is uncertain, another purpose is to redescribe these species in order to understand their relationships better. 

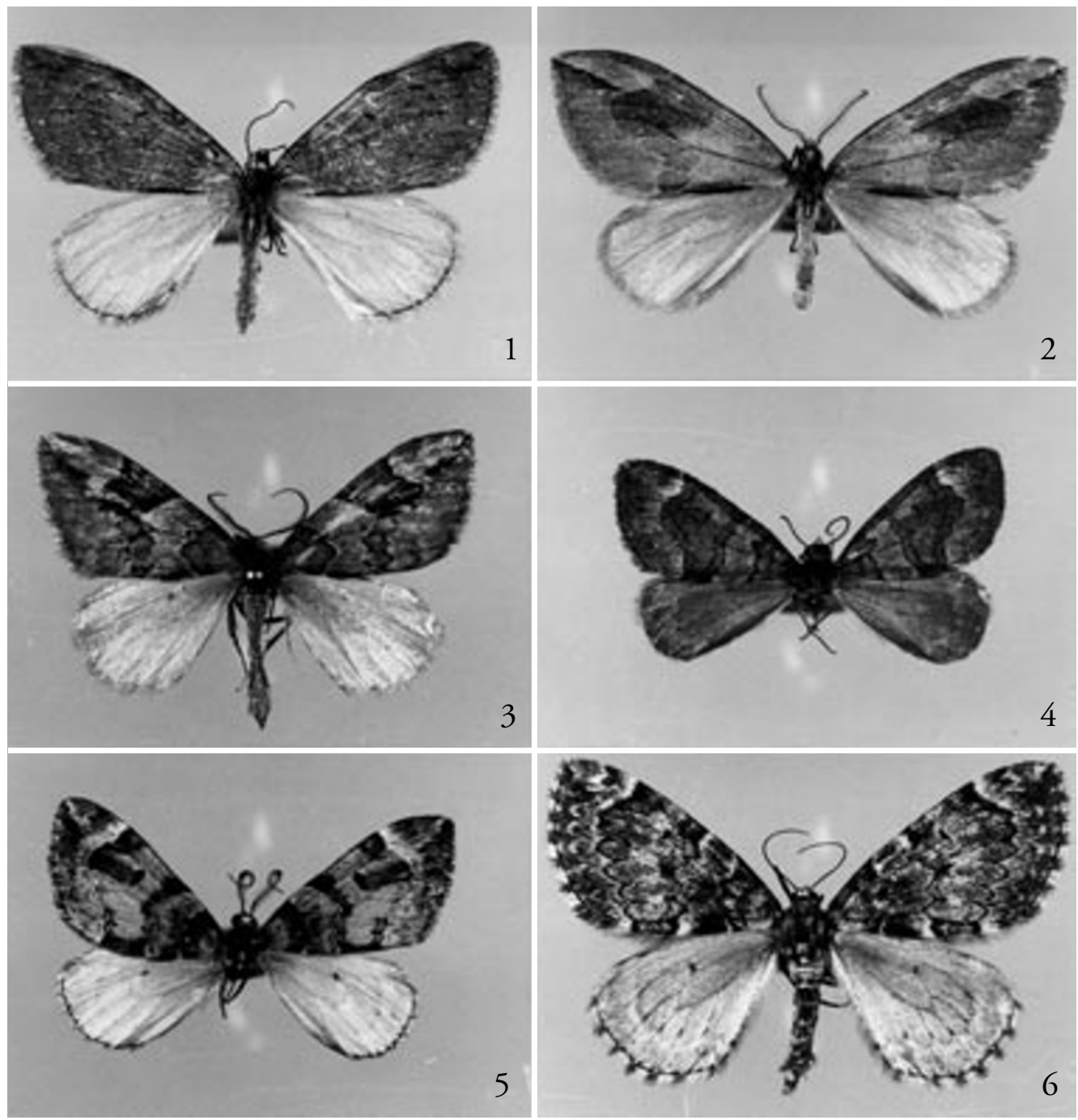

Figs. 1-6. Adults of Heterothera. - 1, H. postalbida; 2, H. tephroptilus; 3, H. mussooriensis; 4, H. undulata; 5, H. hoenei; 6, H. quadrifulta.

\section{Materials AND METHODS}

The study is based on the material from the following museums and private collections:

AMNH, American Museum of Natural History, New York

BMNH, British Museum (Natural History), London BNHM, Bulgarian Natural History Museum, Sofia HNHM, Hungarian Natural History Museum,

Budapest

KY, private collection of Katsumi Yazaki, Tokyo
MF, private collection of M. Fibiger, Copenhagen SNHM, Swedish Natural History Museum,

Stockholm

ZBI, Institute of Botany and Zoology, Tartu ZFMK, Zoologisches Forschungsinstitut und

Museum Alexander Koenig, Bonn

ZMH, Zoological Museum, Helsinki zSM, Zoologische Staatssammlung München, München.

Examination and dissection of the genitalia, in- 
cluding everting the vesica, follow Hardwick (1950), while the terminology of the morphology including the genitalia follows Forbes (1948) and Klots (1970).

\section{Systematics}

\section{Heterothera Inoue, 1943}

Heterothera Inoue, 1943: 12. Type species: Cidaria postalbida Wileman, 1911 (original designation).

Viidaleppia Inoue, 1982: 283. Type species: Cidaria quadrifulta Prout, 1938 (original designation).

\section{Diagnosis and monophyly}

Species of Heterothera are characterized by the sclerotized costa and the triangular sacculus of the male genitalia, the well developed sterigma and the greatly modified ductus bursae of the female genitalia. The species of Heterothera have male antenna and a wing pattern similar to the species of Pennithera Viidalepp, Praethera Viiddalepp and Thera Stephens. However, Heterothera can be distinguished from other taxa by the triangular and sclerotized sacculus, several large spinular cornuti, the well developed sterigma and the greatly modified ductus bursae.

The monophyly of Heterothera s.l. has been defined by Choi (1997), and seven synapomorphies support the clade of Heterothera: (1) small process of sacculus (or harpe), (2) long hairs on the cucullus, (3) medially invaginated saccus, (4) scattered cornuti, (5) semi-circular lamella antevaginalis, (6) relatively thick ductus bursae, and (7) sclerites on the wall of the ductus bursae.

\section{Description}

Antenna of male filiform (postalbida, yunnanensis, sororcula, obscurata, eclinosis), bipectinate with short pectinations (dentifasciata, distinctata, quadrifulta, taigana, undulata) or with long pectinations (incerta, tephroptilus, consimilis, mussooriensis, firmata, serraria, serrataria, kurenzovi, hoenei). Frons smooth, covered with blackish or dark ochreous and whitish scales. Labial palp variable in length, often about twice as long as eye diameter. Interantennal fillet dark brownish in colour, often distinct by white scales. Legs blackish or dark ochreous and whitish, with distinct whitish tibial joints. Metathorax mediodorsally white, with blackish tufts. Forewing ground colour varies; basal part dark, occasionally white, basal line dentate, slanted, occasionally smooth, vertical; dorsum between basal and antemedial lines with a black horizontal streak (postalbida, sororcula, tephroptilus, etes, mussooriensis) or with a vertical blackish bar (yunnanensis, taigana) or with a large dot (quadrifulta, consimilis); antemedial line medially indented, occasionally not indented, strongly waved; postmedial line costally slanted, bent, often toothed, medially bulged; central fascia variable in width, form constant throughout fascia or thinner at middle and dorsum, discoidal dot blackish, often indistinct by uniting with costal part of antemedial line (etes, firmata), dorsum distinct with blackish scales (incerta, obscurata, dentifasciata, distinctata, triangulata, quadrifulta, undulata, stamineata); subterminal line sometimes present, blackish, scalloped (serraria, serrataria, kurenzovi); termen blackish or dark ochreous. Hindwing ground colour whitish (postalbida, yunnanensis, sororcula, incerta, dentifasciata, distinctata, triangulata, consimilis, quadrifulta, serraria, serrataria, kurenzovi, hoenei, stamineata, eclinosis), yellowish white (etes, firmata), greyish or blackish (obscurata, tephroptilus, taigana, undulata, comitabilis); discoidal dot usually small, often large; postmedial line blackish, usually medially bulged; termen sometimes tinged with blackish (incerta, triangulata, consimilis, quadrifulta, serrataria, kurenzovi, undulata) or with waving subterminal line (serraria).

Male genitalia. - Uncus weakly sclerotized, tapered at bottom or slender, length varies from moderate (postalbida) to long (yunnanensis). Tegumen smaller than the total length of vinculum and saccus, domeshaped or triangular. Saccus concave or medially invaginated (postalbida, dentifasciata, yunnanensis, obscurata, serraria, serrataria, kurenzovi, undulata, eclinosis), broad and flat at bottom (incerta, tephroptilus, distinctata, consimilis, taigana) or round (hoenei, firmata). Juxta sclerotized, broad, occasionally juxta and transtilla form a long tubular structure (postalbi$d a$, sororcula); anellus lobe conspicuous, varies in shape, from simple and digitiform (postalbida, sororcula, obscurata, distinctata, consimilis, firmata, taigana, serrataria, kurenzovi, undulata, hoenei) to large and triangular (yunnanensis, eclinosis) or small and nippleshaped (incerta, tephroptilus, dentifasciata, quadrifulta, serraria), usually long hairs present at apex. Valva distoventrally expanded, with long hairs; costa sclerotized, varies in width, distally wider (postalbida, sororcula, obscurata, tephroptilus, dentifasciata, distinctata, consimilis, taigana, undulata, eclinosis), medially expanded (yunnanensis, incerta, quadrifulta, hoenei, mussooriensis) or medially and distally expanded (firmata, serraria, serrataria, kurenzovi); sacculus distinct, usually sclerotized, with a distal process (yunnanensis, incerta, tephroptilus, dentifasciata, distinctata, consimilis, firmata, quadrifulta, taigana, serraria, serrataria, kurenzovi, hoenei, eclinosis) or two processes (postalbi$d a$, sororcula, obscurata, undulata). Aedeagus sclerotized, slender, cylindrical or basally tapered to an apex, distally scobinated, often large spinular processes around neck present (incerta, kurenzovi); vesica tubular or small, sac-like, cornuti usually present, variable in size, with from small to large spines.

Female genitalia. - Papillae anales weakly sclero- 

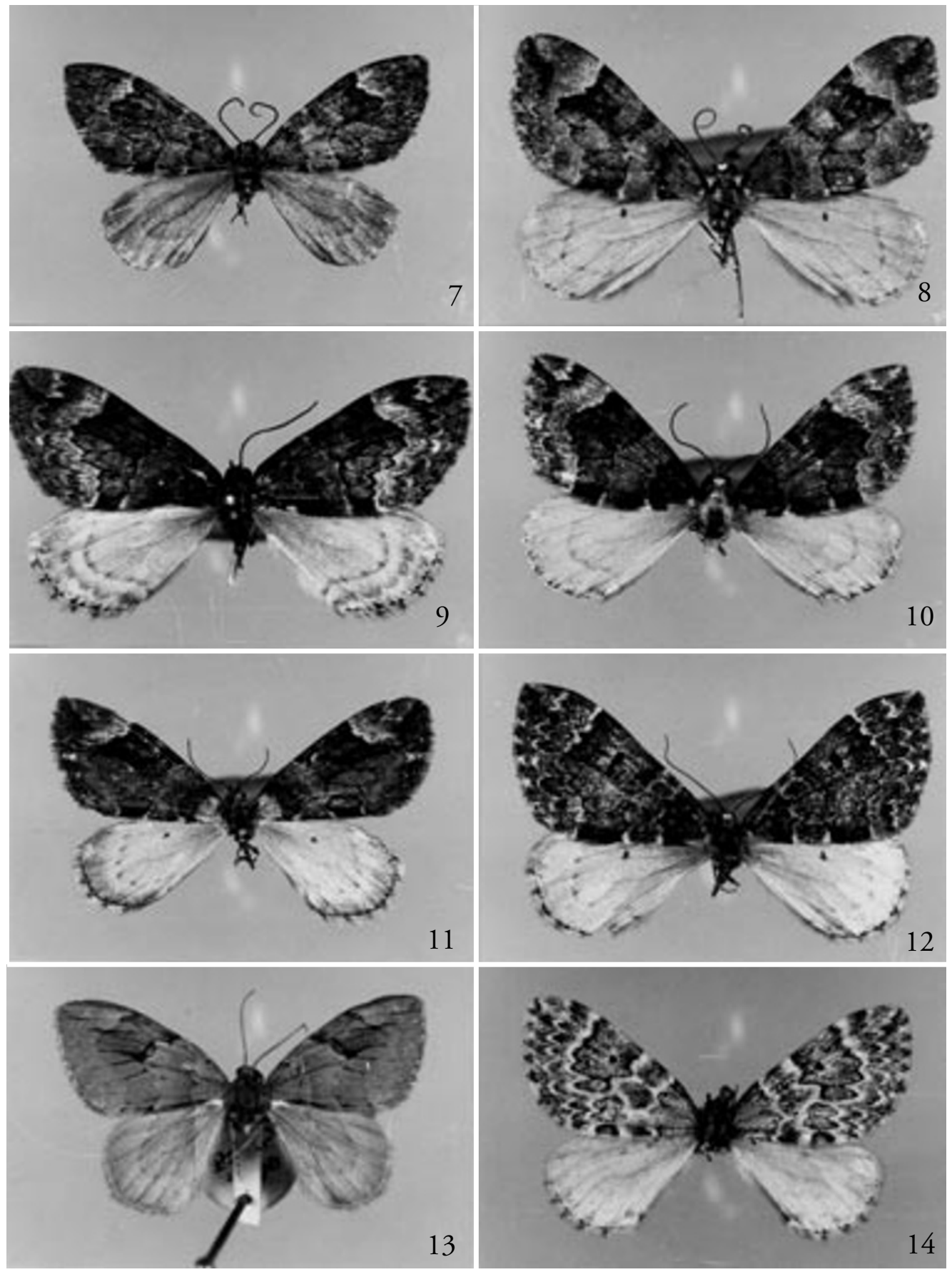

Fig. 7-14. Adults of Heterothera. - 7, H. obscurata; 8, H. distinctata; 9, H. yunnanensis; 10, H. eclinosis; 11, H. triangulata; 12, H. stamineata; 13 , H. etes; $14, H$. kurenzovi. 
tized. Segment 8 membranous or weakly sclerotized. Anterior apophysis varies in length, from $1 / 2$ to $1 / 5$ of posterior apophysis, often anterior apophysis missing (taigana, serraria, serrataria, kurenzovi). Ostium bursae ventrally with lamella antevaginalis bar-shaped (postalbida, yunnanensis, incerta, hoenei, stamineata, eclinosis) or shell-shaped (triangulata); dorsally with lamella postvaginalis forming large horn-like processes (taigana) or semi-round processes densely covered with minute spines (serraria, serrataria, kurenzovi). Ductus bursae varies in length, from very short (serraria, serrataria, kurenzovi) to long, wall with sclerites (postalbida, yunnanensis), sometimes largely expanded from the anterior to the antrum (quadrifulta). Corpus bursae varies in size and shape between species, ovular, membranous (postalbida, incerta, dentifasciata) or strongly sclerotized (serraria, serrataria, kurenzovi), occasionally with appendix bursae (yunnanensis), often wall with minute scobinations; signum usually absent, occasionally with one patch of scobinated signa (taigana sounkeana).

\section{Distribution}

The species of Heterothera are widely distributed in the Palaearctic and Oriental regions, but they are especially abundant in the Oriental region: there are eight species in northern India and Nepal, six species in southwestern China (Tibet), two species in Taiwan, five species in northeastern Asia, one species in the western and eastern Palaearctic and one species in the western Palaearctic only. Some species are quite widely spread throughout the Palaearctic region. For example, $H$. serraria is found from northern Europe to eastern Siberia, $H$. taigana from central Siberia to Kurile Islands and Japan, and H. postalbida from western China to the Korean Peninsula and Japan. On the other hand, many species are endemic to the Oriental region (e.g. the two Taiwanese species $H$. incerta and sororcula).

\section{Remarks}

The bipectinated male antenna was used as a character for Viidaleppia (Inoue 1986). However, cladistic analyses of the Cidariini (Choi 1997) and of Thera s.l. (Choi unpublished) indicate that the pectination of male antenna is not a synapomorphy of Heterothera, whereas the long pectination of the male antenna is a good diagnostic character for some species of Heterothera (e.g. incerta, tephroptilus, mussooriensis, hoenei).

The anellus lobes of the male genitalia in Heterothera are quite helpful to diagnose taxa, especially those from southwestern China. The lobes are usually digitiform or rounded in the apical part. However, two species, H. eclinosis and yunnanensis, possess great- ly modified anellus lobes: they are apically sharply projected and medially triangular, expanded. Both species occur in southwestern China. Nevertheless, the wing pattern and the genitalia indicate that they are allied to Heterothera and especially, the characters such as the filiform male antenna and lamella postvaginalis of the female genitalia show an affinity to $H$. postalbida.

The presence of spines around the neck of aedeagus is recognized as a derived character for Thera (Viidalepp 1980, Choi 1997). However, this feature is also found in some species of Heterothera (e.g. incer$t a$, dentifasciata, hoenei, and yunnanensis). Therefore, it seems to me that the character is a symplesiomorphy for Thera s.l.

\section{Checklist of Heterothera}

Heterothera Inoue, 1943

H. postalbida (Wileman, 1911)

H. sororcula (Bastelberger 1909)

H. tephroptilus (Fletcher, 1961) comb. n.

H. mussooriensis sp. $\mathbf{n}$.

H. undulata (Warren, 1888) comb. n.

H. hoenei sp. $\mathbf{n}$.

H. incerta (Inoue, 1986)

H. quadrifulta (Prout, 1938)

H. obscurata sp. $\mathbf{n}$.

H. dentifasciata (Hampson, 1895)

H. distinctata sp. $\mathbf{n}$.

H. yunnanensis sp. $\mathbf{n}$.

H. eclinosis sp. n.

$H$. triangulata sp. $\mathbf{n}$.

H. comitabilis (Prout, 1923) comb. $\mathbf{n}$.

H. stamineata sp. n.

H. consimilis (Warren, 1888)

H. etes (Prout, 1926) comb. n.

H. taigana (Djakonov, 1926)

taigana taigana (Djakonov, 1926)

taigana sounkeana (Matsumura, 1927)

taigana ishizukai (Inoue, 1955) syn. n.

H. serraria (Lienig, 1846)

H. serrataria (Prout, 1914) comb. n.

H. kurenzovi Choi, Viidalepp \& Vasjurin sp. n.

H. firmata (Hübner, 1822)

Thera Stephens, 1831

T. cyphoschema (Prout, 1926) incertae sedis atrinotata Joannis, 1929 syn. $\mathbf{n}$.

atrinotata reducta Joannis, 1929 syn. $\mathbf{n}$.

T. exangulata (Warren 1909) incertae sedis

Pennithera Viidalepp, 1980

P. distractata (Sterneck, 1928) comb. n. 

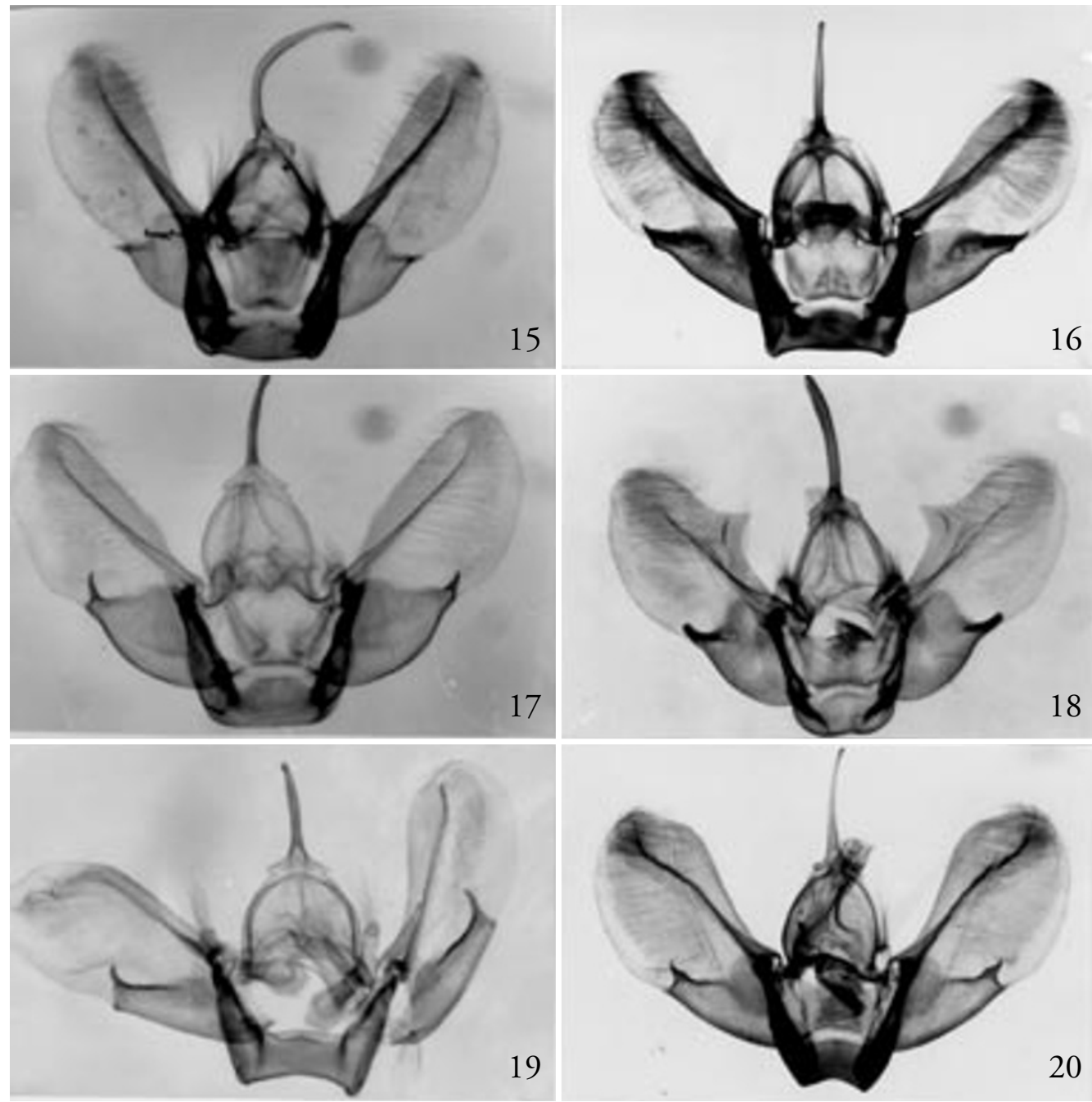

Figs. 15-20. Genital capsule in the male genitalia of Heterothera. - 15, H. tephroptilus; 16, H. undulata; 17, H. incerta; $18, H$. hoenei; 19, H. obscurata; 20, $H$. dentifasciata.

Key to the species of Heterothera (males)

Two species, $H$. triangulata and $H$. stamineata, are not included, because they are only known from females. However, based on the wing pattern elements, $H$. triangulata is similar to $H$. dentifasciata and $H$. stamineata is similar to $H$. comitabilis.

1. Antenna of male bipectinate .2

- Antenna of male filiform. 16

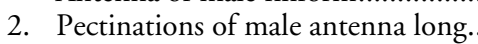

- Pectinations of male antenna short. . .12

3. Dorsum of the forewing with a long black horizontal streak . .4

- Dorsum of the forewing without a black horizontal streak.

4. Postmedial line of the forewing costally ample and round; costa of the valva nearly flat or distally expanded... .5

- Postmedial line of the forewing costally slightly invaginated; costa of the valva basally expanded.. H. mussooriensis 
5. Costa of the valva nearly flat..........H. tephroptilus

- Costa of the valva distally widely expanded H. etes

6. Forewing ground colour blackish ....H. consimilis

- Forewing ground colour whitish or yellowish....7

7. Forewing ground colour whitish .....................8

- Forewing ground colour yellowish ..................10

8. Central fascia of the forewing medially reduced or broken

- Central fascia of the forewing medially not reduced H. serrataria

9. Termen of the hindwing with a blackish waved subterminal line; occurring in Europe, Central and Eastern Siberia.............................H. serraria

- Termen of the hindwing without a blackish waved subterminal line; occurring in the Russian Far East, Korea or Japan ..................H. kurenzovi

10. Forewing with a distinct blackish discoidal dot ... .11

- Forewing with a discoidal dot united to the costal part of antemedial line. H. firmata

11. Central fascia of the forewing medially and dorsally reduced; costa of the valva medially slightly expanded; ductus bursae relatively short, pleated in general H. incerta

- Central fascia of the forewing nearly even in width; costa of the valva medially triangular, expanded; ductus bursae slim, membranous....

H. hoenei

12. Postmedial line of the forewing costally strongly slanting. .13

- Postmedial line of the forewing costally relatively less slanting..... .14

13. Central fascia of the forewing dorsally greatly reduced; interantennal fillet blackish.

H. dentifasciata

- Central fascia of the forewing nearly constant in width; interantennal fillet distinct with white scales.

H. distinctata

14. Central fascia nearly constant in width.

H. taigana

- Central fascia reduced at dorsum . .15

15. Antemedial line of the forewing medially sharply indented; anellus lobe digitiform; ductus bursae anterior to antrum greatly expanded

H. quadrifulta

- Antemedial line of the forewing medially not indented; anellus lobe relatively thick; ductus bursae anterior to antrum not expanded.

H. undulata

16. Black horizontal streak or dot at dorsum between basal and antemedial line of forewing present ..17

- No blackish scales at dorsum between basal and antemedial line of forewing.............. obscurata

17. Presence of a black horizontal streak at the dorsum of forewing.
- Presence of a black spot at the dorsum of forewing.......................................................19

18. Postmedial line of the forewing costally slanting; lamella antevaginalis reduced to small sclerotized process; corpus bursae large H. sororcula

- Postmedial line of the forewing costally convexshaped; lamella antevaginalis well developed with a pair of rod-shaped processes; corpus bursae relatively smaller. H. postalbida

19. Central fascia dorsally reduced; anellus lobe apically sharply projected and dentate, medially triangularly projected; lamella postvaginalis with a pair of large rod-shaped processes.............H. yunnanensis

- Central fascia relatively even in width; anellus lobe apically sharply projected and bifid; lamella postvaginalis simple H. eclinosis

\section{Heterothera postalbida (Wileman)}

(fig. 1)

Cidaria postalbida Wileman, 1911: 325. Holotype ô, JAPAn: Tokyo, Prov[ince]. Musashi, Honshu plains, 29.iv.1895, A.E. Wileman (вмNH) [examined].

Thera postalbida; Prout, 1941: 323.

Cidaria (Thera) postalbida problematica Bryk, 1948: 173. Holotype + , KOREA: Juwool (Shuotsu), 28.vi.1935, (SNHM) [examined]. [Synonymized by Inoue, 1977: 268].

Heterothera postalbida; Inoue, 1943: 12.

\section{Diagnosis}

This species is distinguished by the greyish forewing and whitish hindwing, blackish horizontal streak at dorsum, smooth postmedial line, and the medially reduced central fascia. The male genitalia show the well developed complex of juxta and transtilla, digitiform anellus lobe with an expanded and angled apical part, broad valva with two spinular sacculus processes and apically densely scobinated aedeagus. In the female genitalia, the bar-like sclerotized lamella antevaginalis and a bowl-shaped antrum are characteristic.

\section{Redescription}

Antenna of male filiform. Frons mixed with blackish brown and white, below projected. Labial palp long, 1.5 times to twice of eye diameter. Wingspan 25-34 mm. Forewing ash grey; basal line grey, waved; antemedial line smooth, dorsally greatly incurved; postmedial line smooth, waved, costally and medially bulged, subdorsally indented, dorsum projected; central fascia reduced at bottom, discoidal dot long, blackish; subterminal line whitish and undulating; apical streak blackish; dorsum with long black horizontal streak. Hindwing whitish, with grey discoidal dot; fringe blackish. Thorax greyish, dorsum of metathorax white with blackish tufts. Legs mixed with blackish brown and white, tarsal joints distinct and whitish. 
Male genitalia. - Uncus weakly sclerotized, moderate, basally tapered. Tegumen dome-shaped, basally incurved, with long, sclerotized anal tube. Saccus broad, convex, sclerotized. Juxta and transtilla form a tube-like complex, sclerotized, anellus lobe basally and medially digitiform, apically expanded, triangular, with long hairs. Valva distally broad, round with long hairs; costa flat, sclerotized, sometimes distally expanded; sacculus triangular, sclerotized, two distal spinular projections. Aedeagus slender, distodorsally densely scobinated; vesica tubular, with several minute scobinated cornuti.

Female genitalia. - Papillae anales weakly sclerotized. Anterior apophysis $1 / 3$ length of posterior apophysis. Antrum developed, deep, bowl-like, lamella postvaginalis large bar-like sclerotized processes, lamella antevaginalis thin, round, sclerotized. Ductus bursae medially twisted, with sclerotized walls. Corpus bursae ovate, wall with very minute scobinations.

\section{Distribution}

Japan, Korea, Ussuri, SE China. Sterneck (1928) reported one female from Guanxian, Prov. Sichuan (Kwan-hsien).

\section{Remarks}

Inoue (1943) designated this species as the type of Heterothera. He incorrectly described the uncus of the male genitalia as absent.

Bryk (1948) proposed a new subspecies from Korea, H. postalbida problematica. However, Inoue (1977) synonymized the subspecies with the nominal species. By checking the type specimens and the genitalia, I confirm that subspecific division of the species is unwarranted.

Four species, $H$. postalbida, sororcula, tephroptilus and mussooriensis, are similar to each other in the black horizontal streak along the dorsum of forewing, wing ground colour and the genitalia. However, these four species can be divided into two groups based on the male antennal pectination and the geographic range, ( $H$. postalbida $\&$ sororcula) and ( $H$. tephroptilus $\&$ mussooriensis). Moreover, these species groups can be distinguished by the shape of the dorsal part of sacculus, waved versus straight, and the processes of the male genitalia, sharply pointed versus hooked.

\section{Biology}

The species is bivoltine (Wileman 1911) and in Japan the larva is found only on Pinus densiflora (Sato \& Nakajima 1987).

Additional material examined. - KOREA: Kangwon Prov. Mt. Kumkang-san, 20, 26.v.1985. Dr. A. Vojnits \& L. Zombori; same locality, 2 + , 17-19.ix.1980, Dr. L. Forro \& Gy. Topal; Pyongyang City, Pyongyang No. 1042. Mt. Ry- oungak-san, 1 , 13.x.1987, Korsos \& Ronkay; S. Hwanghae Prov., Haeju, Mt. Suyong-san, No. 1050., 19 , 16.x.1987, Korsos \& Ronkay (HNHM). - JAPAN: Tokyo, 1 ㅇ 10.v.1893, 1 \% , 3.vi.1895, A.E. Wileman (вмNH), 1 б, 1.v.1953, P. Savolainen; Karuizawa, 1 ex., 24.vi.1952. P. Savolainen; Naganohara, 19 , 9.x.1969. J. Kaisila (zMH). CHINA: Wenchow (Prov. Chekiang), 1 , 1913, C.T. Bowring; Foochow (Prov. Fukien), $1 \hat{0}$, April, 1885, Leech (BMNH).

\section{Heterothera sororcula (Bastelberger)}

Thera sororcula Bastelberger, 1909a: 34. Holotype ô, TAIWAN: Arizan, Kagi-Distrikt 7-10000 Fuss. in Senckenberg Museum, Frankfurt [Colour transparency in BMNH, examined].

Dysstroma (Thera) sororcula; Bastelberger, 1909b: 172.

Thera sororcula; Prout, 1941: 323.

Heterothera sororcula; Inoue, 1992: 127.

\section{Diagnosis}

This species is very similar to $H$. postalbida in the wing shape and the genitalia. However, it differs from $H$. postalbida in the distinct central fascia, dark greyish termen, less slanting antemedial line and angled costal part of postmedial line. In the female genitalia the reduced lamella antevaginalis, strongly sclerotized ductus bursae and large corpus bursae are distinguishing features of $H$. sororcula.

\section{Redescription}

Antenna of male filiform. Frons covered with brown and white scales. Labial palp long. Wingspan 27-29 mm. Forewing greyish, basal line blackish, dentate; area between basal and antemedial line tinged with dark grey; antemedial line smooth, slanted; postmedial line smooth, blackish, costally slanted, medially bulged, submedially indented, dorsum slightly bulged; central fascia dark grey, with black discoidal line, dorsally reduced; termen dark greyish, sometimes whitish subterminal line appeared; apical streak blackish line; dorsum with black streak. Hindwing white tinged with grey, with small discoidal dot; fringe blackish. Thorax dark grey, dorsum of metathorax white with black tufts. Legs mixed with brown and white scales, tarsal joints white.

Male genitalia. - Uncus slender, medially expanded. Saccus broad, middle invaginated, anellus lobe digitiform, apical part not expanded, with long hairs. Valva medio- and distoventrally membranous; costa sclerotized, distally wider; sacculus triangular, sclerotized, one large and one minute distal processes. Aedeagus slender, distally scobinated; vesica tubular, cornuti small spines, arranged into two layers.

Female genitalia. - Antrum bowl-like, lamella antevaginalis bar-like, sclerotized processes, ventrally thin and thread-like. Ductus bursae strongly sclerotized and twisted. Corpus bursae large, globular, wall has minute scobinations. 


\section{Distribution}

Taiwan.

\section{Remarks}

Bastelberger (1909a) noted that this species is similar to $H$. consimilis Warren and suggested it might be one subspecies of consimilis. However, he (1909b) placed this species in Dysstroma based on the shape of the male antennae. Prout (1941) noted its closeness to $H$. postalbida.

Material examined. - TAIWAN: Alishan (2200 m), Chiayi,

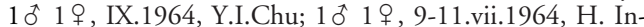
oue; 10, 19-22.vi.1943, M. Owada; Nan-Tou-sien, 10 1959, ех. H. Kezuka (вмNн); Tayuling (2600 m), Hualien Hsien, 10ิ, 26.iii.1987, Y. Shibata; $4 \hat{o}^{\hat{1}} 1$ ㅇ, 1.iv.1984, A. Kawabe; 20 2ㅇ, 1.iv.1984, S. Sugi (вмNн); 19 , 2829.viii.1983; 1 के, 2-4.v.1984; 1 के 1 के, 12-14.iii.1985, H. Yoshimoto (KY); Rantaizan, 7500 ft. 1 ㅇ, 9.v.1909; 10 , 10.v.1909; 1 \%, 15.v.1909, A. E. Wileman (вмNH).

Heterothera tephroptilus (Fletcher) comb. $\mathbf{n}$. (figs. 2, 15, 27, 46)

Thera tephroptilus Fletcher, 1961: 170, figs. 10, 41, 50 \& 51. Holotype 0 , nepal: Mustangbhot, $29^{\circ} 11^{\prime}$ n. Br., $83^{\circ} 58^{\prime}$ ö. L., Tagsa, 4300 m. 24.viii.[19]55, Leg. F. Lobbichler (zsM) [examined].

\section{Diagnosis}

This species is similar to $H$. postalbida in wing shape, but differs in the long, bipectinate male antenna, blackish wing colour, the absence of the discoidal dot, and medially deeply indented antemedial line of forewing.

\section{Redescription}

Antenna of male bipectinate, with long pectinations. Frons mixed with brownish and white. Labial palp blackish, long. Wingspan 26-32 mm. Forewing blackish; basal line blackish; antemedial line costally greatly slanted, dorsally waving; postmedial line costally slanted, medially bulged; central fascia costally dark, discoidal dot absent, medially reduced; dorsum with black horizontal streak; apical streak black line. Hindwing blackish, with weak discoidal dot. Thorax dark grey, dorsum of metathorax white with black tufts.

Male genitalia. - Uncus long, medially bent. Tegumen triangular. Saccus sclerotized, flat at bottom. Juxta broad, sclerotized, anellus lobe short, round. Valva mid-and distoventrally expanded; costally flat, sclerotized; sacculus strongly sclerotized, triangular, with dorsal border undulated, one sclerotized distal spinular process. Aedeagus small, sclerotized surfaces, having a bundle of small spines ventro- and distodorsally, small round vesica with several spinular cornuti, arranged into a circle.

Female genitalia. - Anterior apophysis half length of posterior apophysis. Antrum sclerotized, simple, relatively narrower. Ductus bursae broad, short, with a sclerotized wall. Corpus bursae large, subspherical, membranous.

\section{Distribution \\ Nepal.}

\section{Remarks}

The specimens from Gandaki (Nepal) are smaller (wingspan 26-28 $\mathrm{mm}$ ) than the type specimen (wingspan $32 \mathrm{~mm}$ ).

Additional material examined. - NePAL: Paratypes 10 , Mustangbhot, 29¹1' n. Br., 8358' ö. L., Tagsa, 3500m, 12.viii.[19]55, Leg. F. Lobbichler; 1 옹 same locality, 3800 m, 8.viii.[19]55 (вмNH); Mustangbhot, 29¹1' n. Br., $83^{\circ} 58^{\prime}$ ö. L., Tagsa, 4300 m, 1 q, 24.viii.[19]55, F. Lobbichler (zsm); Gandaki above, Old Marpha $3450 \mathrm{~m}, 10$ 1 , 12.viii.1996, M. Fibiger (ZMн).

\section{Heterothera mussooriensis sp. n.}

(figs. 3, 38, 39)

Type material. - Holotype $\hat{\delta}$, N. India: Mussoorie, 6000', Dehra Dun, U.P., 4.vii.1942 (АMNH). Paratype ô, same locality, 10.vii.1944 (AMNH).

\section{Diagnosis}

This new species is very similar to $H$. tephroptilus in the wing pattern and the male genitalia, but it differs from tephroptilus in the slightly invaginated costal part of the postmedial line of forewing, the discoidal dot of hindwing, and the medially projected valval costa of the male genitalia.

\section{Description}

Antenna of male bipectinate, with long pectinations. Frons mixed with brown and ochreous scales. Labial palp moderate, slightly longer than eye diameter. Legs with yellowish tibial joints. Wingspan 27 $\mathrm{mm}$. Forewing ground colour brownish; basal line waved, medially bulged; antemedial line costally blackish, discoidal dot united with costal part of line, medially deeply indented, dorsally waved; postmedial line costally slanted, medially bulged; central fascia costally blackish, medially and dorsally reduced; dorsum with black horizontal streak; apical streak black line; subterminal line very weak, waved. Hindwing pale brownish; discoidal dot small, blackish.

Male genitalia. - Uncus long, slender, medially bent. Tegumen small, dome-shaped. Juxta broad, sclerotized; anellus lobe long, digitiform, subapically expanded and fused with base of valva, apically long hairs present. Saccus sclerotized, both edges slightly projected. Ventral part of valva medially invaginated, distally largely expanded; costa sclerotized, medially 
projected; sacculus triangular, sclerotized, dorsal border waved, one distal spinular process. Aedeagus cylindrical, distally scobinated; vesica small sac-like; cornuti two bundles of small spines.

Female genitalia. - Unknown.

\section{Distribution \\ N. India.}

\section{Etymology}

The specific name refers to the type locality, Mussoorie, Northern India.

Heterothera undulata (Warren) comb. $\mathbf{n}$. (figs. 4, 16, 28)

Ypsitpetes undulata Warren, 1888: 326. Lectotype ô, here designated “N. INDIA: Thundiani, 29.viii.[18]86." (вмNH). Cidaria (Thera) undulata; Prout, 1938: 111.

Thera undulata; Prout, 1941: 323.

\section{Diagnosis}

$H$. undulata is identified by the blackish wings, double vertical ante- and postmedial lines, and the costally smooth and waving postmedial line of forewing. The species is similar to $H$. hoenei, but it can be distinguished from that by the blackish ground colour of wings and medially less projected costa, angled edges of saccus, and relatively thin sacculus of the male genitalia.

\section{Redescription}

Antenna of male bipectinate, pectinations as short as diameter of shaft. Frons mixed with brownish and white. Labial palp as long as eye diameter. Wingspan 24-33 mm. Forewing dark grey; subbasal line present, blackish, basal line blackish, slanted, costally projected; antemedial line consisted of double vertical lines, slanted, medially slightly indented; postmedial line forming two vertical lines, smooth, medially bulged; central fascia blackish, medially reduced, bottom distinct with blackish scales; termen blackish, subterminal line whitish, waved; apical streak black line. Hindwing dark brownish, with blackish postmedial line. Thorax with blackish tufts.

Male genitalia. - Uncus long and slender. Tegumen dome-shaped. Saccus strongly sclerotized, both edges projected. Anellus lobe short, relatively thick in width, with apically long hairs. Ventral part of valva medially slightly invaginated; costa medially slightly expanded; sacculus strongly sclerotized, triangular, with distally two processes. Aedeagus basally tapered, sclerotized, distally scobinated, vesica with three bundles of cornuti.

Female genitalia. - Anterior apophysis $1 / 3$ length of posterior apophysis. Antrum broad; lamella antevagi- nalis a pair of round projections, densely covered with minute scobinations. Ductus bursae twisted, sclerotized. Corpus bursae ovate.

\section{Distribution \\ India, Nepal.}

\section{Remarks}

Hampson (1895) listed the species under the character "Antennae of male serrate and with fascicles of cilia". Prout (1938) noted that $H$. undulata is similar to Chloroclysta siterata Hufnagel or Hydriomena, but differs in its antennal pectinations. Based on this, he put the species under Thera.

Additional material examined. - N. INDIA: Paralectotypes

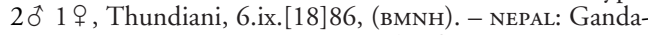
ki above, Old Marpha, 3450m, 1 o 1 \% , 12.viii.1996, M. Fibiger (MF).

\section{Heterothera hoenei sp. $\mathrm{n}$}

(figs. 5, 18, 29, 47)

Type material. - Holotype $\widehat{\phi}$, CHINA: Lijiang (LiKiang), Province Nord-Yunnan, 27.viii.1935, H. Höne (zFMK). Paratypes $2 \hat{0}$, same locality, 27.vii. 1935, 16.viii.1935, H. Höne; 19 , Kangding (Tatsien-Lou), Prov. Sichuan, 18.viii.1898, Chasseurs indigènes (ZFMK).

\section{Diagnosis}

$H$. hoene $i$ is similar to $H$. undulata in the wing pattern elements, but differs from the latter in the strongly bipectinate male antenna, ochreous ground colour of forewing, and whitish hindwing. In the male genitalia, the species is characteristic by the medially triangular process of costa, more or less round saccus, and waving dorsal border of the sacculus and its stellate process.

\section{Description}

Antenna of male bipectinate, with long pectinations. Frons smooth, covered with white and blackish scales. Labial palp ochreous, moderate about as long as eye diameter, sometimes double of eye diameter. Wingspan 24-29 mm. Forewing ground colour ochreous; basal part whitish, basal line relatively thicker, blackish, slanted, bordered with white thin vertical line; area between basal and antemedial line with blackish vertical bar-shaped band; antemedial line blackish, medially indented; postmedial line costally slightly curved, medially bulged; central fascia whitish, sometimes tinged with blackish, discoidal dot large, blackish, dorsally reduced; subterminal line blackish, waved; apical streak blackish; fringe blackish. Hindwing whitish, with small blackish discoidal 
dot; postmedial line blackish; fringe lined with blackish. Metathorax whitish, with black tufts.

Male genitalia. - Uncus moderate, medially bent. Tegumen triangular. Saccus shallow, flat at bottom, often midventrally slightly invaginated. Juxta sclerotized, invaginated at bottom. Anellus lobe short, digitiform. Valva distoventrally membranous, expanded; costa sclerotized, medially triangular projection; sacculus relatively small, with distally stellate process. Aedeagus slender, sclerotized, medially bent; small spinular cornuti present around neck of aedeagus.

Female genitalia. - Anterior apophysis $1 / 4$ length of posterior apophysis. Lamella antevaginalis plate-like, sclerotized processes, densely covered with minute spines. Ductus bursae thin, long. Corpus bursae ovate.

\section{Etymology}

The specific name is given to honour $\mathrm{H}$. Höne, who dedicated his whole life to collecting and studying Chinese Lepidoptera.

\section{Distribution \\ S.W. China.}

\section{Heterothera incerta (Inoue)}

(figs. 17, 30)

Viidaleppia incerta Inoue, 1986: 234, figs 25D, 26. Holotype ๙, TAIWAN: Nengkaoshan, ca. $2800 \mathrm{~m}$, Nantou Hsien, 20.V-2.VI.1966, Ching-Shong Yu (вмNн) [examined]. Heterothera incerta; Choi, 1997: 311.

\section{Diagnosis}

$H$. incerta is identified by the bipectinate male antenna, paler forewing, medially indented antemedial line, the angled costal part of postmedial line, and the distinct dorsum of central fascia and one patch of spinular processes at the distal part of aedeagus. It is similar to quadrifulta in the wing pattern, but incerta is separated from the latter by having the blackish scales at the bottom of the central fascia of forewing, the waving dorsal border of sacculus, and the relatively short and distally pleated ductus bursae.

\section{Redescription}

Antenna of male bipectinate, with long pectinations, basal and distal parts ciliate. Frons mixed with brownish black and white, below projected. Labial palp long, nearly double of eye diameter. Wingspan 26-27 mm. Forewing greyish or dark greyish; subbasal, basal lines blackish; area between basal and antemedial lines with reddish brown band; antemedial line costally slanted, medially indented, below slightly dentate; postmedial line costally slightly angled, slanted, medially bulged, dorsally waved; central fascia dark greyish, dorsally reduced, blackish scales at bottom, discoidal dot blackish; termen reddish brown with whitish scalloped subterminal line; apical streak black line. Hindwing whitish with black discoidal dot; termen greyish with black fringe. Thorax greyish, dorsum of metathorax white with black tufts. Legs mixed with white and brownish black, tarsal joints whitish.

Male genitalia. - Uncus slender, sclerotized, bent. Tegumen dome-shaped. Saccus flat at bottom, sclerotized. Anellus lobe small, nipple-shaped. Ventral part of valva medially expanded; costa medially expanded; sacculus triangular, dorsal border slightly waved, with one spinular process. Aedeagus cylindrical, slightly tapered, distoventrally scobinated and distodorsally a bundle of large spinular processes present; vesica without cornutus.

Female genitalia. - Anterior apophysis $1 / 3$ length of posterior apophysis. Lamella antevaginalis a pair of scobinated large lobes, ventrally semi-round plate structure. Ductus bursae short, distally pleated. Corpus bursae ovate, wall with minute scobinations.

\section{Distribution \\ Taiwan.}

\section{Remarks}

Inoue (1986) noted that this species was similar to Dysstroma citratum (Denis \& Schiffermüller) [incorrect authorship, Linnaeus] on the basis of wing shape, colour and maculation. He also noted that this species was similar to quadrifulta in the male genitalia.

Material examined. - TAIWAN: Mt. Yu Shan (3528 m), Paiyunshanchuang, Kaohsiung Hsien, 1 to 1 \% , 2-3.viii. 1985, M. Nishizawa (KY); Hohuanshan, 3100m, Nantou Hsien, 1 ô 1 ㅇ, 5.viii.1987, A. Kawabe, Coll. Inoue; Nantou Hsien, Formosa, 1 , , 1968, ex. H. Kezula, Coll. Inoue (вмNH).

\section{Heterothera quadrifulta (Prout)}

(fig. 6)

Cidaria (Thera) quadrifulta Prout, 1938: 114. Lectotype ô, here designated "JAPAN: Shinano, 2.viii.1911, coll[ection] Wileman” (вMNH). Asaphodes quadrifulta; Viidalepp, 1980: 64. Viidaleppia quadrifulta; Inoue, 1982: 283. Heterothera quadrifulta; Choi, 1997: 311.

\section{Diagnosis}

The wings of quadrifulta have whitish ground colour with shades of black, a waving antemedial line at the costal part, blackish discoidal dot, white scalloped subterminal line and basally blackish tinged hindwing. This species is similar to $H$. incerta, but differs in the whitish ground colour of forewing and short pectinations of male antenna. Distinguished from $H$. incerta by the middorsal expansion of the costa in the male genitalia and the distally largely expanded ductus bursae of the female genitalia. 

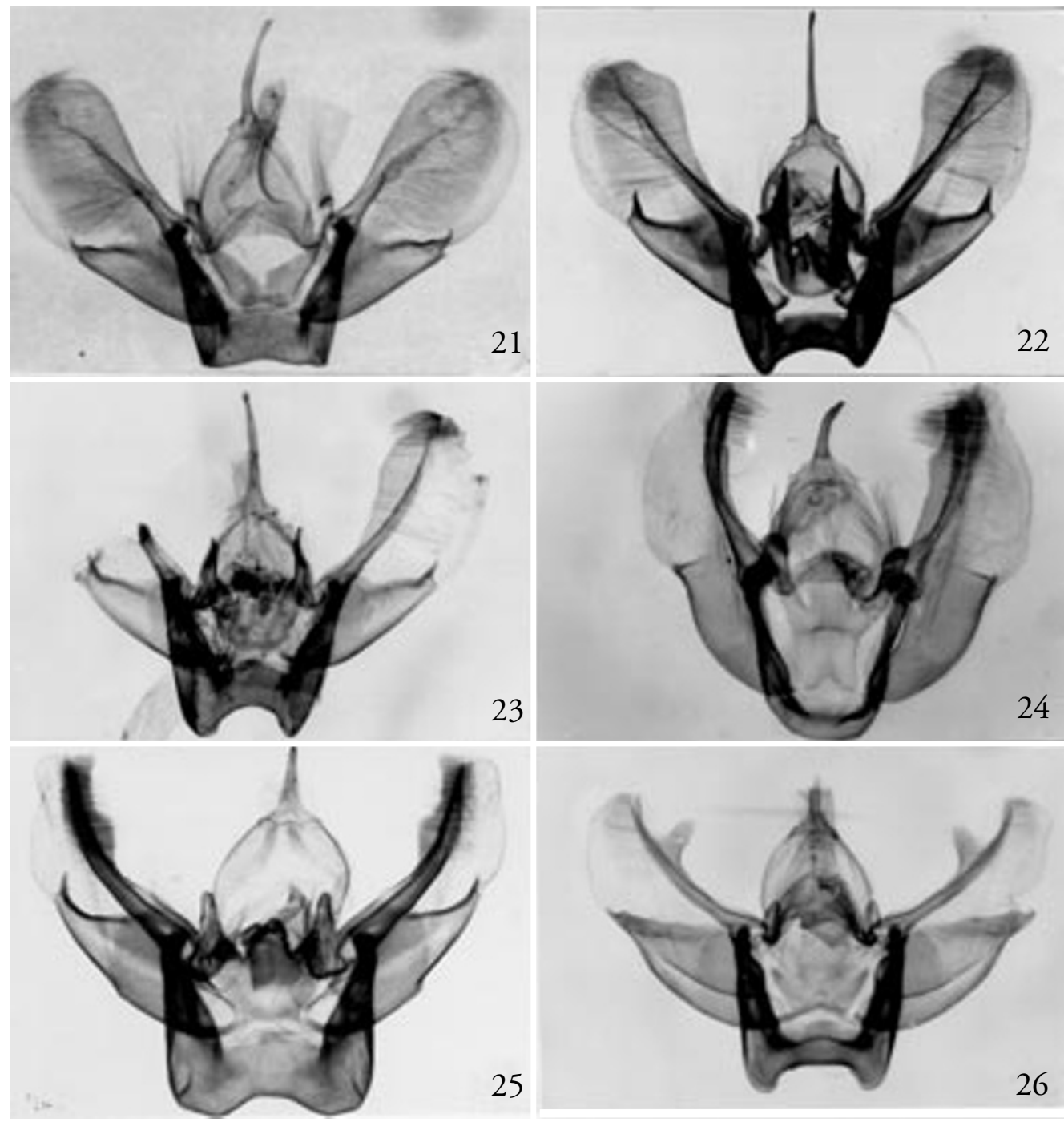

Figs. 21-26. Genital capsule in the male genitalia of Heterothera. - 21, H. distinctata; 22, H. yunnanensis; 23, H. eclinosis; 24, H. firmata; 25, H. serrataria; 26. H. kurenzovi.

\section{Redescription}

Antenna of male bipectinate, with short pectinations, about same width as the shaft. Wingspan $31 \mathrm{~mm}$. Forewing ground colour whitish; basal part dark grey, basal line blackish, slightly dentate; area between basal and antemedial lines with dark grey band; antemedial line costally extended inward, medially indented, dorsally slightly extended inward; postmedial line costally slanted, medially projected, below waved; central fascia greyish, with black discoidal dot, medi- ally reduced, bottom distinct with blackish scales; subterminal line costally blackish, medially whitish, undulating; termen dark grey. Hindwing whitish, termen blackish, with black discoidal dot. Thorax mixed with brownish and white scales with tufts.

Male genitalia. - Uncus long, sclerotized, basally tapered. Tegumen dome-shaped. Anellus lobe small, nipple-shaped. Ventral part of valva medially slightly invaginated; costa sclerotized, middorsally expanded; sacculus triangular, dorsal border nearly straight, with 
one large distal process. Aedeagus distally scobinated; vesica with two bundles of cornuti.

Female genitalia. - Anterior apophysis $1 / 3$ length of posterior apophysis. Lamella antevaginalis tongueshaped with a pair of round patch and densely scobinated. Ductus bursae long, greatly expanded at distal part, wall with rows of spines and sclerites. Corpus bursae membranous, ovate, signum absent.

\section{Distribution \\ Korea, Japan.}

\section{Remarks}

Prout (1938) described the species from two males from Shinano, Japan. He noted that the species is similar to Pennithera comis Butler and Heterothera taigana sounkeana Matsumura, but differs from $P$. comis in the less distinct dorsal dot between basal and antemedial line of forewing. Inoue (1982) designated this species as type species for Viidaleppia.

Additional material examined. - JAPAN: Ontake, Gifuken. 1 $\hat{\delta}, 12-15$.viii.1936, coll. Wileman; Kobushi, Saitama, 10, 4.viii.1953, T. Haruta (BмNH); Mt. Norikuradake, 2600m, Azumi-mura, Nagano, 10 , 6.viii.1988, Y. Kishida; same locality, 1 ㅇ 17.viii.1988, K. Yazaki; Odarumi-toge, Yamanashi, 1 t 1 ㅇ, 29.vii.1990, K. Yazaki (KY). - KOREA: Prov. Ryang-gang, Chann-Pay Plateau, Sam-zi-yan, 1700m, No. 285, 1 ô, 24.vii.1975, J. Papp \& A. Vojnits (нnнм).

\section{Heterothera obscurata sp. n.}

(figs. 7, 19, 31)

Type material. - Holotype $\delta$, w. NEPAL: Karnali, Mugu Dist[rict]., Rara lake 2,990 m, 25- 26.ix.1981, M. Owada, Coll. K. Yazaki (zFmK).

\section{Diagnosis}

This species is quite similar to incerta in wing pattern elements but can be separated from it by the filiform male antenna without pectinations, its greyish wings and by the male genitalia which have a relatively long anellus lobe, a distally expanded costa, a relatively thin sacculus, and scattered spinular cornuti of the vesica.

\section{Description}

Antenna of male filiform. Frons covered with white and blackish scales. Labial palp long, about 1.5 times of eye diameter. Metathorax has blackish tufts. Wingspan $27 \mathrm{~mm}$ in male. Forewing ground colour greyish; basal line dentate; antemedial line medially sharply indented; postmedial line costally slanted, waved, medially bulged; central fascia greyish, with black discoidal dot, blackish scales present at bottom, medially reduced; termen brownish, with weak blackish subterminal line. Hindwing greyish, with blackish postmedial line.
Male genitalia. - Uncus long, sclerotized, medially bent. Tegumen bell-shaped, sclerotized. Saccus sclerotized, medially broadly invaginated. Juxta sclerotized, anellus lobe long, digitiform with hairs on top. Costa of valva strongly sclerotized, distally wider; sacculus triangular, sclerotized, distally two processes with one large and one small. Aedeagus short, cylindrical, distally tapered and scobinated; vesica small, with several large and small spinular cornuti.

Female genitalia. - Unknown.

\section{Etymology}

The specific name refers to the indistinct pattern elements of forewing.

\section{Distribution}

Nepal.

\section{Heterothera dentifasciata (Hampson)}

(figs. 20, 32)

Larentia dentifasciata Hampson, 1895: 379. Lectotype $\delta$, here designated "PAKISTAN: Murree, 1884, Harford coll[ection].” (BMNH).

Cidaria (Thera) dentifascia; Prout, 1914: 219. [Incorrect spelling].

Thera dentifasciata; Prout, 1941: 324.

Viidaleppia dentifasciata; Yazaki, 1994.

Heterothera dentifasciata; Choi, 1997: 311.

\section{Diagnosis}

$H$. dentifasciata is easily identified by the blackish and greatly slanting costal part of postmedial line and large blackish discoidal dot of forewing. The male genitalia of dentifasciata are similar to those of $H . o b$ scurata, but the processes of sacculus and the cornuti of the vesica are different.

\section{Redescription}

Antenna of male bipectinate, with short pectination as long as shaft. Frons mixed with brownish black and white scales. Labial palp long about twice of eye diameter. Wingspan 29-34 mm. Forewing reddish brown or greyish; basal line blackish; antemedial line weakly slanted, medially indented; postmedial line costally strongly slanted, medially bulged; central fascia blackish, medially broader and dorsally reduced, with black discoidal dot; subterminal line blackish and undulating; apical streak blackish line. Hindwing whitish, basal slightly blackish, with black discoidal dot and postmedial line, fringe black. Metathorax middorsally white with black tufts.

Male genitalia. - Uncus long, slender, sclerotized, basally tapered. Tegumen dome-shaped. Saccus sclerotized, medially concave- shaped. Anellus lobe small, digitiform. Ventral part of valva distally wider, with long hairs; costa sclerotized, distally expanded; saccu- 


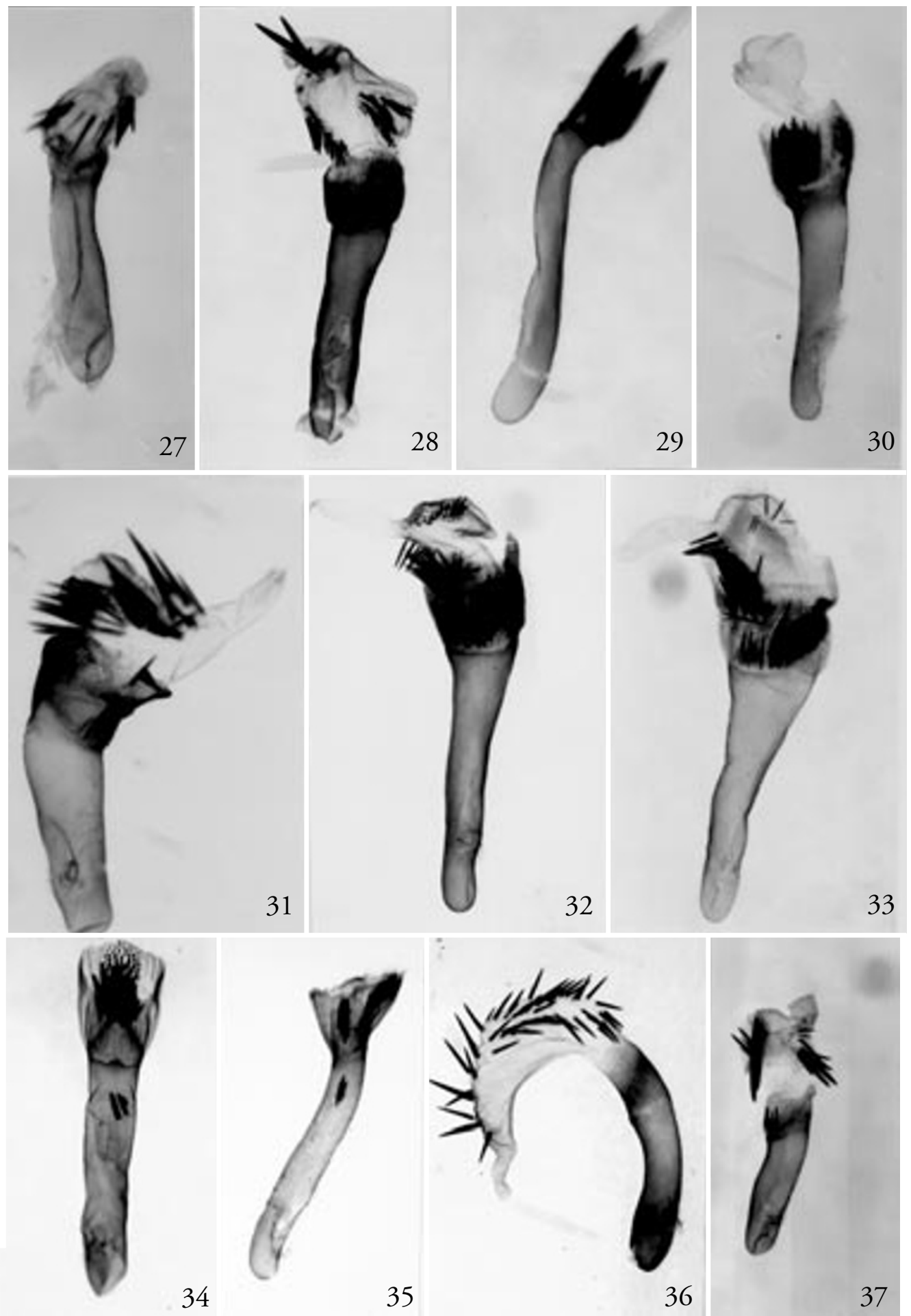


lus triangular, with a distal spinular process. Aedeagus sclerotized, basally tapered, distally scobinated; vesica with two bundles of cornuti.

Female genitalia. - Anterior apophysis half length of posterior apophysis. Antrum broad, strongly sclerotized. Ductus bursae twisted, relatively short, thick. Corpus bursae small, ovate.

\section{Distribution \\ India, Pakistan, Nepal.}

\section{Remarks}

Hampson (1895) listed the species with Pennithera comis under the character "Antennae of the male with two pairs of short cilia-bearing processes from each joint". Prout (1938) noted that the species is similar to consimilis in the colour of central fascia and it is also similar to Thera exangulata Warren, but differs from $T$. exangulata by the less waved basal line of forewing, pale hindwing and the angled postmedial line of hindwing.

Additional material examined. - NEPAL: Central N. Ganesh Himal. Nesim 2200m, 2ô, 23.x.1995, M. Fibiger;

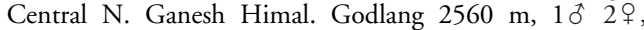
13.x.1995, M. Fibiger; Sagarmatha N.P., $27^{\circ} 49^{\prime}$ N $86^{\circ} 44^{\prime}$ E, Kyang Juma, 3600 m, 1ㅇ, 19.v.1996, A. Albrecht, O. Bistrom, K. Mikkola \& A. Wikberg; Sagarmatha N.P., $27^{\circ} 48^{\prime} \mathrm{N} 86^{\circ} 44^{\prime} \mathrm{E}$, Syanboche, 3800 m, 2 9 , 22.v.1996, A. Albrecht, O. Bistrom, K. Mikkola \& A. Wikberg (zмH); W. Nepal, Karnali, Mugu Dist. Rara Lake, 2990 m, 1 đo, 2526.ix.1981, M. Owada (KY); Bagmati Rasuwa, Yuli Karka, 3375 m, 1 \% , 12-13.v.1993, T. Haruta (KY).

\section{Heterothera distinctata sp. $\mathrm{n}$.}

(figs. 8, 21, 33)

Type material. - Holotype $\delta^{\star}$, CHINA: Lijiang (LiKiang), Province Nord-Yunnan, 21.iv.1935, H. Höne (ZFMK).

\section{Diagnosis}

The new species is identified by the short pectinations of the male antenna, whitish interantennal fillet, ochreous forewing, whitish hindwing, and the strongly slanted costal part of the postmedial line of forewing. This new species is very similar to dentifasciata in the wing shape and the male genitalia, but it can be distinguished from dentifasciata by the whitish interantennal fillet and the even width of central fascia, which is not reduced at the middle and dorsum of fascia.

\section{Description}

Antenna of male bipectinate, with short pectinations. Interantennal fillet and frons white. Labial palp moderate. Legs dark ochreous, with whitish tibial joints. Metathorax with whitish hairs on middorsum, with black tufts. Wingspan $29 \mathrm{~mm}$ in male. Forewing ground colour yellow ochreous; basal line blackish, nearly vertical; area between basal and antemedial line tinged with blackish scales; antemedial line blackish, medially indented; postmedial line costally slanted, medially bulged; central fascia ochreous, discoidal dot one large blackish, dorsally distinct with blackish scales; subterminal line blackish and undulating; apical streak blackish line. Hindwing whitish, with black discoidal dot; postmedial line blackish, medially bulged.

Male genitalia. - Uncus sclerotized, medially bent, moderate in length, as long as height of tegumen. Tegumen triangular. Saccus sclerotized, broad and flat at bottom. Juxta sclerotized. Anellus lobe small, digitiform, with hairs on top. Costa sclerotized, distally largely expanded; sacculus triangular, sclerotized, distally with a hooked process. Aedeagus distally tapered, sclerotized; vesica small, sac-like, cornuti mixed with small and medium spinular processes, located around neck and middle of vesica.

Female genitalia. - Unknown.

\section{Etymology}

The specific name refers to the diagnostic wing pattern elements of the forewing.

\section{Distribution}

S.W. China.

\section{Heterothera yunnanensis sp. $\mathrm{n}$.}

(figs. 9, 22, 34, 48)

Type material. - Holotype $\delta^{\top}$, CHINA: Lijiang (LiKiang), Province Nord-Yunnan. 27.vi.1935, H. Höne (ZFMK); Paratype 9 , CHINA: A-tun-tse (Nord-Yunnan), Talsohle ca. 3000m, 4.vii.1937, H. Höne (ZFMK).

\section{Diagnosis}

H. yunnanensis is distinguished by the blackish and greatly reduced central fascia at the middle and dorsal parts and the black horizontal streak along the dorsum of basal part and central fascia. The anellus lobes of the male genitalia, apically sharp and pointed, medially triangular and expanded, are characteristic. This new species is quite similar to $H$. dentifasciata in wing shape,

Figs. 27-37. Aedeagus with everted vesica of Heterothera. - 27, H. tephroptilus; 28, H. undulata; 29, H. hoenei; 30, H. incerta; 31, H. obscurata; 32, H. dentifasciata; 33, H. distinctata; 34, H. yunnanensis; 35, H. eclinosis; 36. H, serrataria; 37, $H$. kurenzovi. 

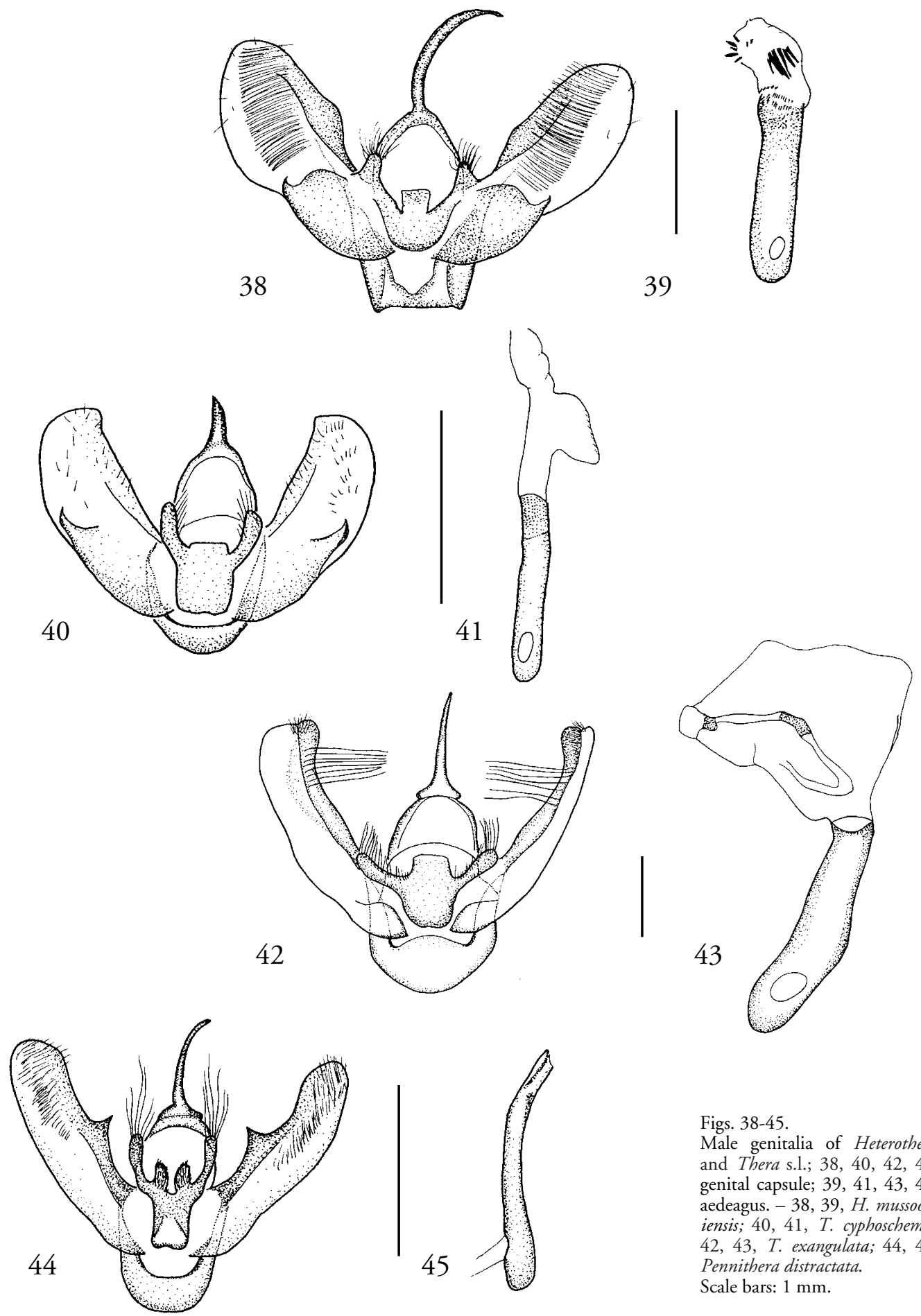

Figs. 38-45.

Male genitalia of Heterothera and Thera s.l.; 38, 40, 42, 44, genital capsule; 39, 41, 43, 45, aedeagus. $-38,39, H$. mussoor iensis; 40, 41, T. cyphoschema; 42, 43, T. exangulata; 44, 45, Pennithera distractata. Scale bars: $1 \mathrm{~mm}$. 
but it can be distinguished from $H$. dentifasciata by the filiform male antenna, black streak at the dorsum of forewing, the anellus lobe and the cornuti of the vesica. The lamella antevaginalis of the female genitalia, with a rod-shaped process, is similar to $H$. postalbida.

\section{Description}

Antenna of male filiform. Frons mixed with white and blackish brown scales. Labial palp moderate in length. Legs mixed with white and blackish brown. Metathorax blackish, with black tufts. Wingspan 32 $\mathrm{mm}$ in male, $36 \mathrm{~mm}$ in female. Forewing ground colour greyish; basal line blackish, consisting of double vertical lines, dentate; antemedial line medially slightly indented, slanting from costa to dorsum; postmedial line costally smooth, slanted, medially bulged, dorsally waving; central fascia blackish, medially and dorsally greatly reduced, dorsally blackish; border of costal part of postmedial line lined with whitish; subterminal line blackish and undulating; termen greyish; apical streak black line; dorsum between basal and antemedial lines with black bar. Hindwing whitish; postmedial line blackish, double vertical lines; fringe dotted with black.

Male genitalia. - Uncus slender, long, about 1.5 times the height of tegumen. Tegumen bell- shaped. Saccus medially invaginated. Juxta round at bottom, sclerotized. Anellus lobe medially triangular, sclerotized, apically sharp, slightly bifurcated. Costa sclerotized, medially wider; sacculus triangular, sclerotized, distally spine-like process. Aedeagus slender, sclerotized; cornuti comprised of three bundles of spinular processes at ventro- and dorsobasal part and middle part of vesica.

Female genitalia. - Papillae anales weakly sclerotized. 8th segment weakly sclerotized. Lamella antevaginalis laterally a pair of large spinular spines, ventrally a pair of ring-like sclerotized processes with densely covered small spines. Ductus bursae short, with sclerotized wall. Corpus bursae large with one large appendix bursae.

\section{Etymology}

The specific name refers to the type locality, Yunnan.

\section{Distribution \\ S.W. China.}

Heterothera eclinosis sp. n.

(figs. 10, 23, 35, 49)

Type material. - Holotype $\hat{\sigma}$, CHINA: Taibaishan (Tapaishan im Tsinling), Sued-Shensi, 30.vi.1935, L.

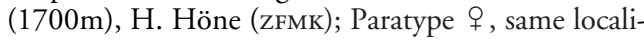

ty, 16.v.1936, H. Höne (zFmK).

\section{Diagnosis}

H. eclinosis is characterized by the slanted and dorsally blackish central fascia of forewing. It is similar to $H$. yunnanensis in the wing pattern and the male genitalia, but it can be distinguished by its smaller size, ochreous ground colour of wings and relatively constant width of central fascia and the medially not expanded anellus lobe of the male genitalia and the general structure of the female genitalia.

\section{Description}

Antenna of male filiform. Frons with white and blackish scales. Labial palp long, about 1.5 times the eye diameter. Legs dorsally blackish, with whitish tibial joints. Thorax dorsally white, metathorax with blackish tufts. Wingspan $27 \mathrm{~mm}$ in male, $30 \mathrm{~mm}$ in female. Forewing ground colour ochreous; basal area dark ochreous, basal line waving; antemedial line greatly slanted, medially indented; postmedial line medially bulged, slightly waving; central fascia dark ochreous, dorsally slightly reduced; termen blackish, subterminal line whitish, undulating; apical streak blackish line; dorsum with black dot. Hindwing white, with small discoidal dot; postmedial line light blackish, medially bulged; fringe black.

Male genitalia. - Uncus strongly sclerotized, long, about twice of height of tegumen. Tegumen triangular. Saccus sclerotized, medially invaginated. Juxta sclerotized. Anellus lobe sclerotized, long, rod-shaped, medially elbowed, apically bifurcated. Costa sclerotized, distally wider; sacculus triangular, sclerotized, with a distal spinular process. Aedeagus slender, sclerotized; cornuti small spinular process, present on basal and middle parts of vesica.

Female genitalia.- Anterior apophysis $1 / 3$ length of posterior apophysis. Lamella antevaginalis a pair of triangular plates which are densely covered with small spines. Antrum thin, sclerotized. Ductus bursae relatively short, sclerotized. Corpus bursae with ovate appendix bursae, without signum, wall has minute scobinations.

\section{Etymology}

The specific name refers to the sloping central fascia of the forewing.

\section{Distribution}

S.W. China.

Additional material examined. - CHINA: Taibaishan (Tapaishan im Tsinling), Sued- Shensi, 10 , 2.vii.1935, 19 23.vi.1935, H. Höne. (вмNH). 
Heterothera triangulata sp. $\mathrm{n}$.

(figs. 11, 50)

Type material. - Holotype + , CHINA: Lijiang (Likiang), Province Nord-Yunnan, 25.ix.1935, H. Höne (ZFMK).

\section{Diagnosis}

This species is very similar to $H$. dentifasciata in the central fascia. However, it can be distinguished from the latter by its smaller wings, less indented antemedial line, and the lamella antevaginalis and ductus bursae of the female genitalia.

\section{Description}

Antenna of female filiform. Frons mixed with white and blackish scales, with blackish projecting hairs below. Labial palp long, double the eye diameter. Legs mixed with white and blackish scales, and whitish tibial joints. Metathorax whitish at middorsum, with blackish tufts. Wingspan $27 \mathrm{~mm}$ in female. Forewing ground colour ochreous; basal part whitish, basal line relatively thicker, blackish; antemedial line smooth, medially slightly indented; postmedial line costally strongly slanted, medially bulged; central fascia tinged with blackish scales, with large discoidal dot, medially reduced, dorsally distinct and blackish; subterminal line weak, whitish vertical line; apical streak blackish line. Hindwing whitish, with small black discoidal dot; blackish postmedial line, medially bulged; termen blackish.

Male genitalia. - Unknown.

Female genitalia. - 8th segment long, with weakly sclerotized surface. Lamella antevaginalis shell-like processes. Antrum thin, sclerotized. Ductus bursae relatively thin, long. Corpus bursae ovate, without signum.

\section{Etymology}

The specific name refers to the triangular central fascia of forewing.

\section{Distribution \\ S.W. China.}

\section{Heterothera comitabilis (Prout) comb. $\mathbf{n}$.}

Larentia comis Hampson, 1895: 379 (in part), nec Butler. Thera comitabilis Prout, 1923: 198. Holotype $\widehat{\delta}$, N. INDIA: Sikkim, Jongri, 13000 ft., 1887, ex. coll. Elwes (BMNH) [examined].

\section{Diagnosis}

The waved costal part of postmedial line, the relatively thicker and the blackish subterminal line of forewing and blackish hindwing are characteristic features of comitabilis. The species is similar to $H$. stamineata, but differs in the costally toothed postmedi- al line of forewing and blackish ground colour of hindwing.

\section{Redescription}

Antenna of male bipectinate with short pectinations. Frons covered with dark ochreous and white scales. Labial palp long, double of eye diameter. Interantennal fillet whitish. Wingspan $30 \mathrm{~mm}$. Forewing dark ochreous; basal part blackish, basal line distinct with whitish; area between basal and antemedial line with blackish bar; antemedial line medially indented; postmedial line costally dentate, slightly tinged with white, medially bulged; central fascia blackish, with black discoidal dot; subterminal line thick, blackish, undulating. Hindwing pale blackish; discoidal dot blackish; postmedial line paler; fringe black.

Male genitalia and female genitalia not examined (see remarks below).

\section{Distribution \\ N. India.}

\section{Remarks}

Prout (1923: 198) noted that the species is similar to Pennithera comis Butler in the antennal structure, but differs in the short branches of antenna. He also noted that the species is similar to Electrophaes coryla$t a$ in the darkish coloration.

The genitalia of comitabilis are not examined because the types listed were lacking their abdomens. The placement of the species in Heterothera is based on the shape of wing pattern elements which is similar to $H$. stamineata.

Additional material examined. - Paratype $q$, N. INDIA. Sikkim, Tonglo, July 1886, Collectio[n] H.J. Elwes. (BMNH).

\section{Heterothera stamineata sp. $\mathrm{n}$.}

(figs. 12, 51)

Type material. - Holotype $q$, CHINA: Lijiang (Likiang), Province Nord-Yunnan, 4.vii.1935, H. Höne (ZFMK); Paratype 9 , same locality, O, 17.vi.1935, H. Höne (ZFMK).

\section{Diagnosis}

The new species is similar to comitabilis in the shape of the wings, but differs in the whitish ground colour of the hindwing.

\section{Description}

Antenna of female filiform. Frons covered with white and blackish scales. Labial palp length twice the eye diameter. Metathorax with blackish tufts. Wingspan $30-31 \mathrm{~mm}$ in female. Forewing ground colour brownish; basal part dark brownish, basal line den- 
tate; antemedial line bordered with whitish, costally slanted, medially and dorsally nearly vertical; postmedial line costally bordered with whitish line, medially bulged; central fascia brownish, discoidal dot black, bottom blackish; subterminal line blackish, undulating; fringe dotted with blackish. Hindwing whitish, with black discoidal dot; postmedial line blackish; fringe lined with black.

Male genitalia. - Unknown.

Female genitalia. -8 th segment weakly sclerotized. Anterior apophysis $1 / 4$ length of posterior apophysis. Lamella antevaginalis a plate-like process, densely covered with small spinular spines, ventrally with semicircular sclerotized plate. Ductus bursae relatively short, thin. Corpus bursae ovate, without signum.

\section{Etymology}

The specific name refers to the shape of the threadlike central fascia.

\section{Distribution \\ S.W. China.}

\section{Heterothera consimilis (Warren)}

(fig. 52)

Thera consimilis Warren, 1888: 326. Holotype 0 , N. INDIA: Thundiani, 9.x.[18]86, Genitalia slide No. 3986. (вмNн) [examined]

Larentia consimilis; Hampson 1895: 380.

Heterothera consimilis; Choi 1997: 311.

\section{Diagnosis}

$H$. consimilis is easily identified by the wavy central fascia and dentate basal line of the forewing. In the female genitalia the thick and sclerotized ductus bursae is characteristic. This species is similar to $H$. etes in wing pattern, but differs in the blackish ground colour of wings.

\section{Redescription}

Antenna of male bipectinate, with long pectinations, tip and base filiform. Frons mixed with brownish and white scales. Labial palp long, twice diameter of eye. Thorax mixed with brownish and white scales, with tufts. Wingspan 24-29 mm. Forewing ground colour dark greyish or blackish; veins of basal part on blackish streak; subbasal line blackish, round; basal line black, dentate; area between basal and antemedial line with weak blackish band; antemedial line costally slanted, medially and dorsally waved; postmedial line costally straight, often bent, slanting, medially bulged, below waving, dorsally bulged; central fascia dark grey, with black discoidal line, sometimes medially and dorsally reduced; dorsum with large reddish dot; termen dark greyish with white undulating subterminal line; apical streak a black line. Hind- wing whitish, termen dark greyish, with small black discoidal dot.

Male genitalia. - Uncus long, sclerotized, and slightly bent in middle. Tegumen triangular. Saccus flat at bottom and sclerotized. Anellus lobe small, digitiform. Ventral part of valva distally slightly expanded; costa sclerotized, medially very wider; sacculus triangular, dorsal border waved, with one distal large sclerotized spine. Aedeagus distally scobinated, with round vesica and cornuti in two bundles.

Female genitalia.- Anterior apophysis $1 / 3$ length of posterior apophysis. Antrum simple, unmodified. Ductus bursae thick, wall sclerotized. Corpus bursae ovate, small.

\section{Distribution}

India, Nepal, Afghanistan.

\section{Remarks}

Warren (1888) described the species based on five males and one female from Thundiani and noted that the species is closely related to Thera juniperata. Prout $(1938,1941)$ wrote that this species is similar to $T$. cupressata Herrich-Schäffer in the wing colour and he also pointed out the colour and size variation among the specimens of Thundiani, Kashmir and Simla.

Additional material examined. - INDIA: Paratype 19 , Thundiani, 2.v.[18]87, Genitalia slide No. 3987; Simla, 7000

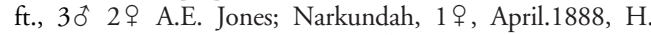
McArthur coll.; Goorais Valley, 10 , June1887, J.H. Leech; Kashmir, Gulmorg, 3ô, 10.vi.[19]31, 12.vi.[19]31, 16.vi. [19]31, Fletcher coll. (вмNн); West Bengal, Darjeeling Dist. Tonglu, 3040 m, 2 ㅇ, 6.xi.1981, M. Owada (KY); N-Indien, Uttar Pradesh, Kumson Himalaya, Dist. Nainital, Bhimtal, 1500m, 1 ㅇ, 15-30.v.1990, A. Hauenstein (ZFMK). - NEPAL: Mustangbhot, $29^{\circ} 11^{\prime}$ n. Br., $83^{\circ} 58^{\prime}$ ö. L., Tagsa, 3500 m. 9.vii.[19]55, F. Lobbichler (BMNH); Gandaki above, Old Marpha. 3450m, 1ô, 12.viii.1996, M. Fibiger; 15 km SW, Kathmandu Hattiban pine for., 1500m, 1+, 2.iii.1995, K. Mikkola \& A. Wikberg; Godavari, $27^{\circ} 40^{\prime} \mathrm{N} 85^{\circ} 25^{\prime} \mathrm{E}, 15 \mathrm{Km}$ SE Kathmandu, 1500 m, 1 \%, 25.v.1996, A. Albrecht, O. Bistrom, K. Mikkola \& A. Wikberg (zмH); Kathmandu, Godavari 1600m, 10, 18.vii.1990, K. Yazaki (KY). - AFGHANISTAN: Afghanistan, $19,84-41$, Fletcher coll. (BMNH).

\section{Heterothera etes (Prout) comb. $\mathbf{n}$.}

(figs. 13, 53)

Thera etes Prout, 1926: 251. Holotype ô, N. India: Assam $5000 \mathrm{ft}$. Shillong, Nov[ember] 1924, Fletcher leg. (BмNH) [examined]

\section{Diagnosis}

The species is very similar to $H$. consimilis in the wings and genitalia, but differs in the greyish wing ground colour, the process of sacculus and the three bundles of cornuti of the vesica. 


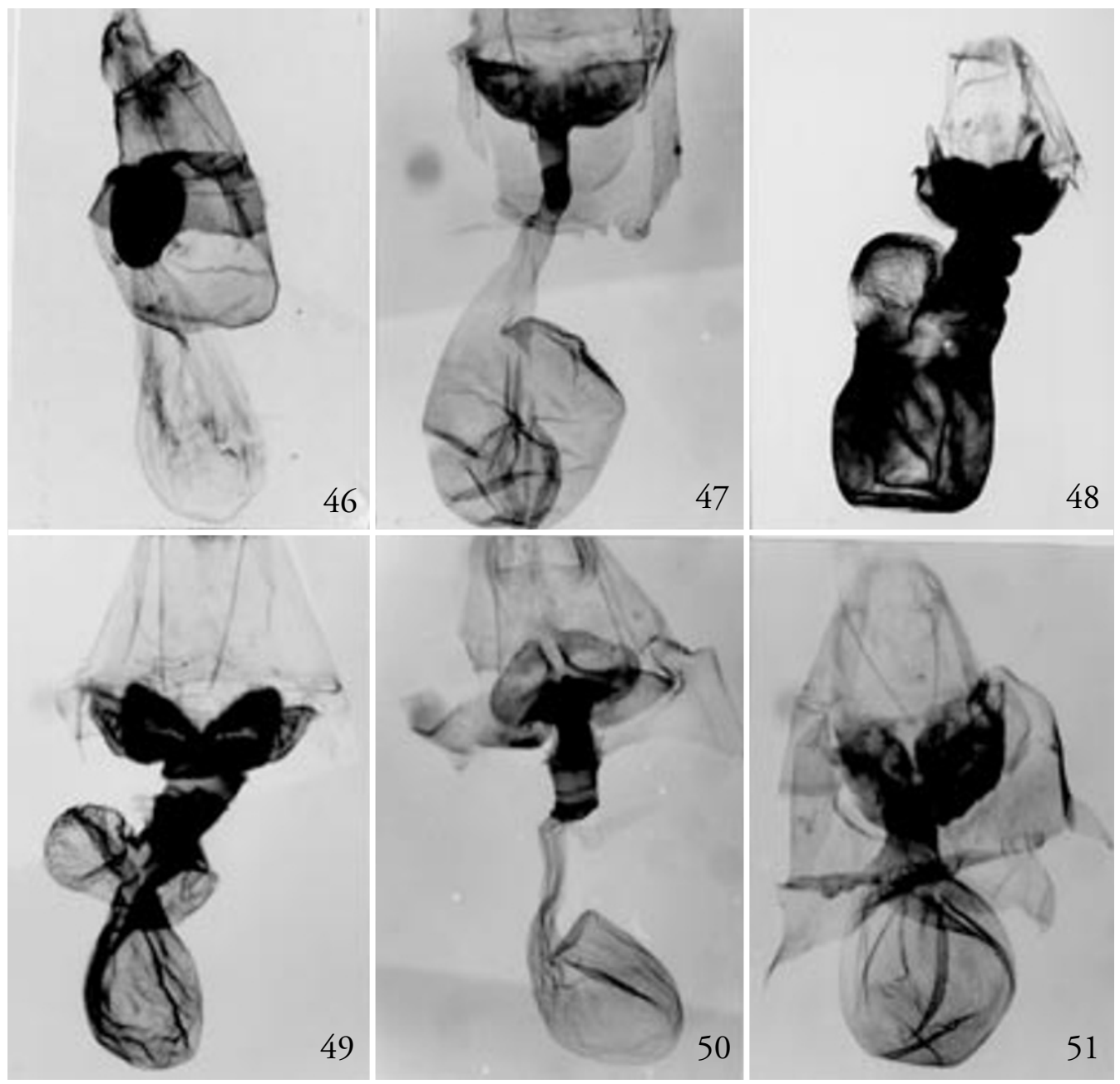

Figs. 45-51. Female genitalia of Heterothera. - 46, H. tephroptilus; 47, H. hoenei; 48, H. yunnanensis; 49, H. eclinosis; 50, H. triangulata; 51, H. stamineata.

\section{Redescription}

Antenna of male bipectinate, with long pectinations. Frons mixed with yellowish and yellowish brown scales, smooth. Labial palp long, about 1.5 times of eye diameter. Legs yellowish and yellowish brown. Metathorax with blackish tufts. Wingspan $26 \mathrm{~mm}$. Forewing ground colour greyish; basal line blackish, dentate; antemedial line costally blackish, largely waved at middle and dorsum, medially indented; postmedial line blackish, medially and dorsally bulged; central fascia waved, discoidal dot long and distinct by uniting with costal part of antemedial line; subterminal line indistinct, pale whitish; apical streak light black- ish; dorsum with black horizontal streak. Hindwing yellowish white; blackish postmedial line.

Male genitalia. - Uncus sclerotized, long about twice of tegumen height. Tegumen dome-shaped. Saccus broad, sclerotized, medially slightly invaginated. Juxta broad, sclerotized; anellus lobe long, digitiform, apically expanded with long hairs. Ventral part of valva medially invaginated, distally wide with a patch of hairs; costa sclerotized, medially much wider; sacculus triangular, dorsal border waved, with one distal process. Aedeagus cylindrical, sclerotized, medially slightly bent, distally densely scobinated; vesica small sac-like, cornuti spinular processes in three patches. 
Female genitalia. - Papillae anales weakly sclerotized. Anterior apophysis 1/5 length of posterior apophysis. Antrum simple. Ductus bursae moderate, wall with sclerotized process. Corpus bursae ovate, signum absent.

\section{Distribution \\ N. India.}

\section{Remarks}

Prout (1926) noted that the species is similar to Pennithera comis Butler and $H$. consimilis Warren. However, he distinguished etes based on its smaller size, reddish and weakly marked wing pattern elements and slender male abdomen. He (1941) noted that the species is somewhat similar to Thera cyphoschema Prout or T. atrinotata Joannis in the wing pattern, but it can be distinguished by the male antennal pectination.

Additional material examined. - INDIA: Paratypes $2 q$, Assam 5000ft. Shillong, 2.vi.1924, Fletcher leg.; Khasis, 5000 ft. Shillong, 10, 25.v.1923, Fletcher coll.; Assam, Shillong, 1 ㅇ, H.M. Parish (вмNн).

\section{Heterothera taigana taigana (Djakonov)}

Cidaria taigana Djakonov, 1926: 27. Holotype ô, Russia: Sajan Mountains. Kasyr, E. Minusinsk, 7.viii.[19]24, L. \&

I. Koshantschikov (Djakonov 1926: 27) [not examined]. Asaphodes taigana; Viidalepp 1980: 65.

Viidaleppia taigana; Inoue 1982: 283.

Heterothera taigana; Choi 1997: 311.

\section{Diagnosis}

$H$. taigana is characterized by the dark ochreous or blackish ground colour of wings, small blackish dot at the dorsum and the costally smooth waving postmedial line of forewing. In the male genitalia the uncus, anellus lobe, costa, and sacculus are characteristic. The females of taigana are distinguished by the very large horn-like lamella postvaginalis.

\section{Redescription}

Antenna of male bipectinate, with short pectinations. Frons blackish. Labial palp about 1.5 times as long as eye diameter. Legs blackish with white tibial joints. Wingspan 27-33 mm. Forewing ochreous brown; basal line blackish, forming two vertical lines, waved, slanted; antemedial line waved, medially indented; postmedial line black, medially round, bulged; central fascia even in width, with black discoidal dot; subterminal line blackish, round; dorsum between basal and antemedial lines distinct with black dot. Hindwing blackish; discoidal dot black, small; postmedial line blackish.

Male genitalia. - Uncus sclerotized, twice as long as tegumen, basally tapered, medially bent. Tegumen dome-shaped. Saccus shallow, broad. Anellus lobe large, horizontally expanded, rod-shaped, with long hairs on dorsal part. Valva sclerotized in general, distoventrally membranous; costa largely sclerotized, with distal end blunted; sacculus large, triangular, ventrally very slender, distoventrally with sharply pointed process. Aedeagus long, slender, sclerotized, distally scobinated; vesica tubular with small diverticula; cornuti mixed with large and small spines.

Female genitalia. -8 th segment sclerotized. Anterior apophysis absent. Posterior apophysis long, slender. Lamella postvaginalis with large horn-like sclerotized process; lamella antevaginalis plate-like, sclerotized. Ductus bursae short, broad, wall with sclerotized processes. Corpus bursae slightly slender or ovate.

\section{Distribution}

Russia (eastern Siberia).

\section{Remarks}

Djakonov (1926) noted its closeness to the firma$t a$-group in the wing pattern.

Material examined. - RUssia: Irkutskaja obl., Hamar-Daban, taiga, Meteorolog st. 1450 m, 6 ô 1 9 , 25-27.vii.1984, ad. luc. Mikkola \& Viitasaari; Magadan obl., Upper Kolyma r. $62^{\circ} \mathrm{N} 149^{\circ} 40^{\prime} \mathrm{E}, 600 \mathrm{~m}$ scree slope ad. luc., $1 \delta^{\star}$, 16.vii. 1987, K. Mikkola; $59^{\circ} 10^{\prime} \mathrm{N} 150^{\circ} \mathrm{E}$, Magad. obl., Ohkotsk coast, $100 \mathrm{Km} \mathrm{W.} \mathrm{Magadan,} 10$ 2 \% 4-6.viii.1989, K. Mikkola (zMH); Baikal, SW coast, Shumilikha river, 1 t , 10.viii.1972, (ZMI).

\section{Heterothera taigana sounkeana (Matsumura)}

Cidaria (Thera) sounkeana Matsumura, 1927: 184. Holotype $\delta$, JAPAn: Sounkei, Hokkaido (Mt. Daisetsu), 9.viii. 1926, Matsumura leg. [not examined].

Thera kurilaria Bryk, 1942: 70. [Synonymized by Inoue 1955: 72]

Thera kurilaria ecce Bryk, 1942: 71. [Synonymized by Inoue 1955: 72].

Cidaria hospes Djakonov, 1955: 318.

Asaphodes sounkeana; Viidalepp 1980: 65

Viidaleppia taigana sounkeana; Inoue 1982: 283.

Thera taigana ishizukai Inoue, 1955: 72. Holotype ô, JAPAN: Mt. Jonen (2500m), Japan Alps, Nagano Pref. 26.vii.1951, H. Inoue (BMNH) [examined]. syn. n.

\section{Diagnosis}

This subspecies is separated from the nominal subspecies by the presence of the signum in the corpus bursae.

\section{Distribution}

The Russian Far East, Japan.

\section{Remarks}

Inoue (1955) noted that Thera kurilaria Bryk might be the same species as sounkeana Matsumura on 

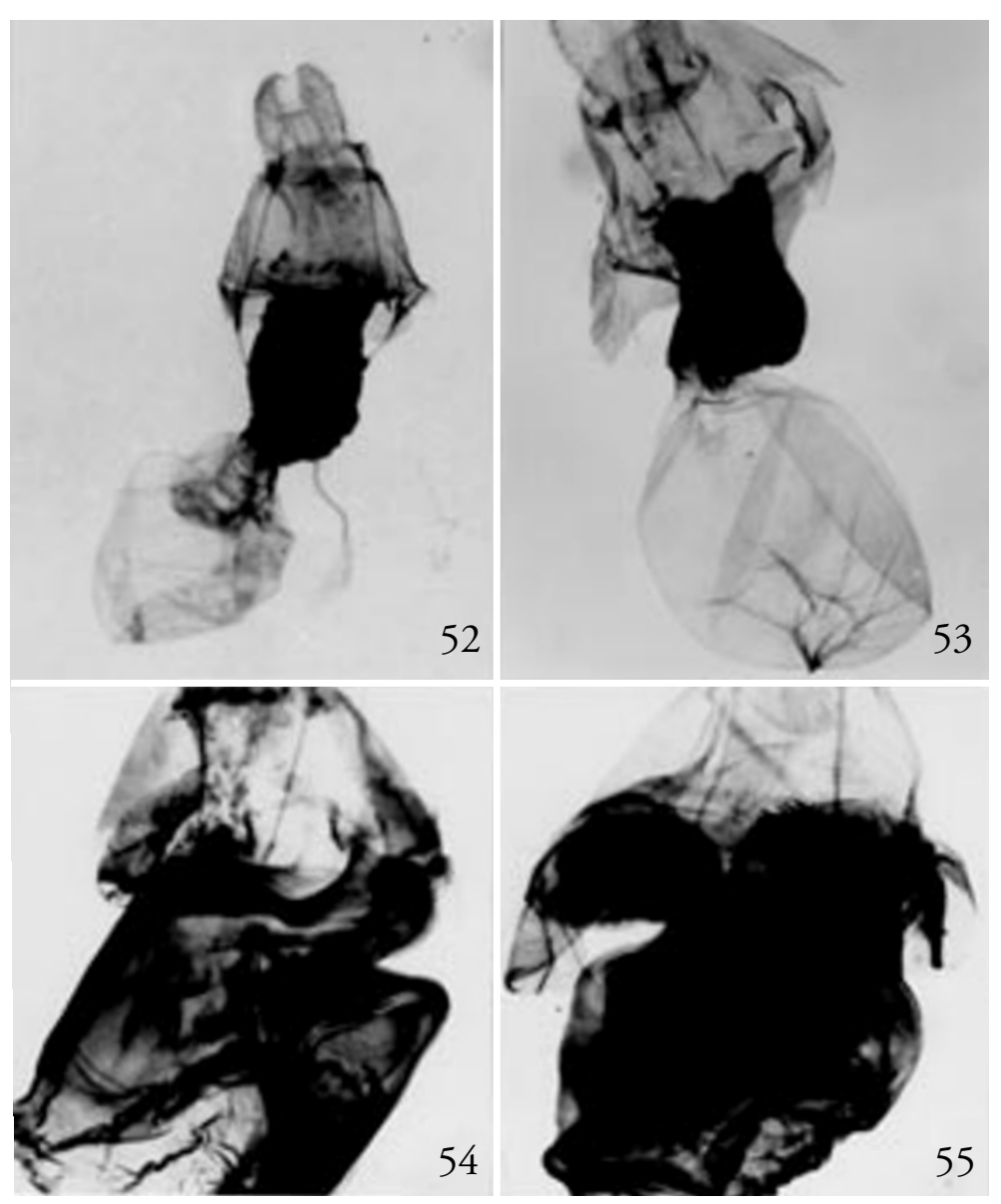

Figs. 52-55.

Female genitalia of Heterothera. $-52, H$. consimilis; $53, H$. etes; 54, H. serraria; 55, H. kurenzovi.

the basis of the length of forewing and the structure of male genitalia. He $(1977,1982)$ listed two subspecies of taigana in Japan, sounkeana and ishizukai.

The subspecies sounkeana has the derived feature in the female genitalia; the presence of one signum patch in corpus bursae. This subspecies ranges from Amur through Kurile Islands to Japan.

In the original description of ishizukai, Inoue (1955: 72) wrote the differences between these two subspecies: "larger, and a little lighter in colour and postmedian line of forewing more weakly incurved in cellule 6, discal fleck a little less heavier than sounkeana." I have checked 3 type specimens of ishizukai, and the subspecific rank of ishizukai compared to sounkeana was very doubtful. Thus, I synonymized ishizukai with sounkeana.

\section{Biology}

Pinus pumila Regel is known as a host plant in Japan (Sato \& Nakajima 1987).

Material examined. - RUssia: Kemorovo obl. Gornaya, Shoriya, 1 , 24.viii.1965, Kononenko; Kurilid, Itunup, 10, 25.vii.1979, V. Junno; Sahhalin, Birjusinka, L., 1 ㅇ , 7 10.vii.1975, Viidalepp ; Kuriilid, Kunasir, Tretjakovo, 1 우 22- 24.vii.1980, Pototski, Ruben \& Veldre (ZBI). - JAPAN: Mt. Daisetsu, Hokkaido, 1 đ 2 ㅇ, 29.vii.1978, Y. Kishida; Kamikawa Mt. Daisetsu, Hokkaido, 10ิ, 20- 21.viii.1993, H. Kobayashi (Ky); Mt. Mitsumata Range 2560 m, 1 ex., 4.viii.1954, T. Haruta (ZMH). 


\section{Heterothera serraria (Lienig)}

(fig. 54)

Cidaria serraria Lienig, 1846: 200. Holotype BALTIC (LATVIA). [not examined]

Gnophos serraria Herrich-Schäffer, 1847: 72.

Cidaria lienigiaria Lederer, 1853: 183 [Synonymized by Staudinger \& Wocke 1871: 184].

Cidaria serraria Zeller; Staudinger \& Wocke 1871: 184, Prout 1914: 219 [Incorrect authorship].

Melanippe ziczaccata Schöyen, 1875: 145. [Synonymized by Prout 1914: 219].

Larentia serraria ab. continua Strand, 1903: 16.

Larentia serraria ab. albida Stichel, 1911: 86.

Larentia serraria ab. spania Stichel, 1911: 86.

Asaphodes serraria; Viidalepp 1977: 576.

Viidaleppia serraria; Inoue 1986: 61.

Heterothera serraria; Choi 1997: 311.

\section{Diagnosis}

$H$. serraria is characterized by the whitish ground colour, blackish dots between basal and antemedial lines, medially broken central fascia, white and scalloped subterminal line of forewing and the blackish and scalloped subterminal line of hindwing. In the female genitalia, the antrum and very short and heavily sclerotized ductus bursae are distinguishing features. This species is very similar to the following two species, $H$. serrataria and kurenzovi, but differs in the termen of hindwing and the sterigma of female genitalia.

\section{Redescription}

Antenna of male bipectinate, with long pectinations. Frons whitish, round. Labial palp short, less than eye diameter. Metathorax dorsally white with blackish tufts. Wingspan 21-26 mm in male, 27-29 $\mathrm{mm}$ in female. Forewing ground colour whitish; basal line black, dentate; area between basal and antemedial line with blackish vertical band; antemedial line medially slightly indented; postmedial line costally waved, medially bulged; central fascia blackish, sometimes medially missing or reduced, discoidal dot large, blackish; termen blackish, subterminal line white, waving. Hindwing whitish; discoidal dot blackish; termen black with whitish, waving subterminal line. 1st tergal sclerite minute.

Male genitalia. - Uncus thin, shorter than tegumen, medially slightly bent. Tegumen bell-shaped. Saccus medially indented, broad. Juxta broad, sclerotized. Anellus lobe small round, sclerotized, very short hairs on top. Valva distally tapered; costa sclerotized, with medial expansion; sacculus well developed, distoventrally a large process. Aedeagus cylindrical, sclerotized; vesica tubular, cornuti large spinular.

Female genitalia. - Anterior apophysis absent, posterior apophysis long, slender. Lamella postvaginalis semi-circular covered with minute spines, lamella antevaginalis sclerotized, V-shaped with medially invaginated. Ductus bursae very short. Corpus bursae large, posteriorly strongly sclerotized, with sclerotized striations at anterior part. Signum absent.

\section{Distribution}

Northern Europe to eastern Siberia.

\section{Remarks}

The H. serraria-group, comprising three species, H. serraria, serrataria and kurenzovi, is characterized by the wing pattern and the female genitalia. Among these species, the latter two species are sympatric in the Russian Far East. The species fly concurrently during July in southern Ussuri and Habarovsk. The species kurenzovi can be distinguished by more blackish coloration of the wing pattern elements and especially, by the genitalia of both sexes. The distal part of the aedeagus in serrataria is sclerotized and the cornuti are more or less small spinular processes, but the aedeagus of kurenzovi is distally sclerotized and also several spines are present at the vesica and the cornuti are the mixture of large and small spines in the vesica. In the female genitalia, the lamella antevaginalis of serrataria is a pair of triangular processes, whereas that of kurenzovi is a pair of rectangular processes.

\section{Biology}

Probably Picea is the host plant, and the species hibernates in the larval stage (Mikkola et al. 1985).

Material examined. - FINLAND: Seinäjoki,1 ô 1 ㅇ, 30.vi. 1931; Porvoo, Aminsby, 1 đ 1 1 , 23.vi.1959, 24.vi.1970, E. Suomalainen. - Russia: Murmansk district, $65 \mathrm{Km} \mathrm{S}$. Monchegorsk, 3 ơ 2 q , 19.vii.1993, A. Lvovsky; Murmansk district, Luvenga, White sea shore, 2 o 1 q , 29.vi.1989, M. Ko-

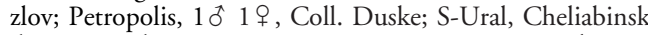
dist., Iremel mountain reserve, 900-1300 m, 7ô, 2327.vi.1996, K. Nupponen, J.-P. Kaitila, J. Junnilainen \& M. Ahola; Altai Sibr., 1, Coll. Winter; Irkutskaja obl., Hamar-Daban, taiga, Meteorolog st. 1450 m, 13 đ 4 , , 2527.vii.1984, ad. luc. Mikkola \& Viitasaari; Buryatia, $53^{\circ} 13^{\prime} \mathrm{N} 109^{\circ} 19^{\prime} \mathrm{E}$, Barguzin valley $1000 \mathrm{~m}$, Ust- BarguzinYambul rd. taiga, 50े, 13.vii.1996, Jalava \& Kullberg (zMH).

\section{Heterothera serrataria (Prout) comb. $\mathbf{n}$.}

(figs. 25, 36)

Cidaria (Thera) serraria serrataria Prout, 1914: 219. Holotype $\delta$, RUSSIAN FAR EAST: Kasakewitsch, Ussuri, in Coll. Püngeler (Prout 1914: 219) [not examined].

Cidaria (Thera) serrataria; Prout 1938: 115.

Asaphodes serrataria; Viidalepp 1977: 576.

Viidaleppia serrataria; Inoue 1986: 60.

\section{Diagnosis}

$H$. serrataria is very similar to $H$. serraria, but differs in the complete central fascia, the termen of hindwing without blackish subterminal line, the digitiform anellus lobe, the deep saccus and the lamella post- and antevaginalis. 


\section{Redescription}

Antenna of male bipectinate, with long pectinations. Frons brownish black. Labial palp short, less than eye diameter. Wingspan 24-28 mm. Forewing ground colour whitish; basal line blackish, dentate; blackish vertical dots between basal and antemedial lines; antemedial line costally largely toothed, medially indented; postmedial line costally toothed with one deep invagination, medially bulged; central fascia blackish, with blackish discoidal dot; termen blackish; subterminal line waving, whitish. Hindwing whitish; basal blackish, with weak discoidal dot; postmedial line blackish. 1st tergal sclerite moderate projection.

Male genitalia. - Uncus short, sclerotized, basally tapered. Tegumen bell-shaped. Saccus broad, medially indented. Juxta broad, basally round. Anellus lobe digitiform, small hairs on top. Valva slim, distoventrally expanded; costa sclerotized, medially and distally expanded; sacculus triangular, sclerotized, distoventrally with process. Aedeagus cylindrical, distally strongly sclerotized; vesica tubular, cornuti spinular.

Female genitalia. - Anterior apophysis absent, posterior apophysis long, slender. Lamella postvaginalis large round processes with toothed surfaces, lamella antevaginalis broad, V-shaped, medially hollowed, covered with spines. Ductus bursae short, heavily sclerotized. Corpus bursae large, strongly sclerotized, with broad opening.

\section{Distribution \\ The Russian Far East, Japan.}

\section{Remarks}

Inoue (1986) listed this species under Viidaleppia on the basis of the genitalia. However, he was uncertain of its generic status because the species showed slender pectinations in male antenna which was similar to Pennithera, and single areole of forewing which was exceptional in Thera- group.

Jaros et al. (1992) recorded the species H. serraria from the Korean Peninsula. However, the record is very suspicious based on the distribution and I suppose that the specimen might be $H$. serrataria or kurenzovi.

Material examined. - RUSSIA: S-Ussuri, $10 \hat{0} 19$, 912.vii.1976, Tsugujevski rj. DVNTS, Berjzovoi stats. DRL. Metsavir, Viidalepp, Ruben \& Vasjurin; Habarovsk, Nelma, 2 + , 16-26.vii.1977, Viidalepp, Laanetu \& Talve (zBI); Pompejefka, Amur, $2 \hat{\sigma} 1$ 으 (BMNH). - JAPAN: Mt. Peipan, Asahikawa C. 1ठิ, 12.vii.83, Y. Kusunoki (BмNH).

Heterothera kurenzovi Choi,Viidalepp \& Vasjurin sp.n. (figs. 14, 26, 37, 55)

Pennithera kurenzovi Viidalepp 1996: 23. [nomen nudum]

Type material. - Holotype $\hat{\jmath}$, RUSSIAN FAR EAST:
Habarovsk, Nelma, 16-26.vii.1977, Viidalepp, Laanetu \& Talve leg. (zBI). Paratype 1 i S-Ussuri, Tsugujevski rj. DVNTS, Berjzovoi stats. DRL, Metsavir, 912.vii.1976, Viidalepp, Ruben \& Vasjurin (ZBI).

\section{Diagnosis}

This species is very similar to $H$. serrataria, but differs in the more or less dark wing elements and medially broken central fascia. The long spinular processes at the distal part of the aedeagus, the very large spinular cornuti and the sterigma of the female genitalia are characteristic.

\section{Description}

Antenna of male bipectinate, with long pectinations. Frons brownish black. Labial palp short, less than eye diameter. Metathorax dorsally white with blackish tufts. Wingspan 26-28 mm. Forewing ground colour whitish; basal part blackish, basal line dentate; next to basal line are blackish, vertical dots; antemedial line costally and dorsally projected inward, medially indented; postmedial line generally waved, medially bulged; central fascia blackish, with strong blackish discoidal dot, medially broken; termen with round blackish, vertical band, subterminal line white, waved. Hindwing whitish, discoidal dot very weak; termen weak blackish spots. Metathorax whitish. 1st tergal sclerite with moderate process.

Male genitalia. - Uncus short, sclerotized, basally tapered. Tegumen bell-shaped. Saccus broad, medially indented. Juxta broad, sclerotized. Anellus lobe digitiform, apically with very short hairs. Valva basally broad, distally reduced; costa slender, sclerotized, medially largely expanded; sacculus triangular, sclerotized, distoventrally with a claw-like process. Aedeagus cylindrical, distally with spinular processes, cornuti large, spinular, scattered.

Female genitalia. - Anterior apophysis absent, posterior apophyses long, slender. Lamella postvaginalis semi- circular processes with dentate surfaces, lamella antevaginalis large plate-like structure densely covered with sclerotized processes. Ductus bursae very short, sclerotized. Corpus bursae large, opening with strongly sclerotized, anterior part with sclerotized striations.

\section{Distribution}

The Russian Far East (Primorye, Sikhote Alin Mts.), Sakhalin, N. Japan (Viidalepp 1996).

\section{Remarks}

Originally, the new species was described a decade ago by Viidalepp and Vasjurin on the basis of the material which is now preserved in the Institute of Biology and Pedology, Vladivostok. However, unfortunately this description had not yet been published. During my preparation of Heterothera, Dr. Viidalepp 
kindly provided the material. Thus, here, we are describing this species jointly.

\section{Heterothera firmata (Hübner)}

(fig. 24)

Geometra firmata Hübner, 1822: 515. Holotype Europe [not examined].

Thera consobrinata Curtis, 1834: 519 [Synonymized by Prout 1914: 219].

Thera simulata Stephens, 1831: 271 nec. Hübner, 1822 [Synonymized by Staudinger \& Wocke 1871: 184].

Chesias ulicata Rambur 1834: 394; Staudinger \& Wocke 1871: 184, Prout 1914: 219.

Larentia firmata; Herrich-Schäffer 1847: 171.

Cidaria firmata; Staudinger \& Wocke 1871: 184.

Thera firmata; Viidalepp 1977: 576.

Thera firmata ab. approximata Lempke, 1950: 163.

Thera firmata ab. brunneofasciata Lempke, 1950: 163.

Thera firmata ab. grisescens Lempke, 1950: 163.

Thera firmata ab. interrupta Lempke, 1950: 163.

Thera firmata ab. purpureobrunnea Cockayne, 1952: 267.

Asaphodes (Pennithera) firmata; Viidalepp 1980: 70.

Heterothera firmata; Choi 1997: 311.

\section{Diagnosis}

The wing pattern elements and the wing colour of $H$. firmata are somewhat similar to Thera obeliscata. However, firmata can be easily distinguished by the bipectinate male antenna, strongly indented antemedial line and the blackish discoidal line that is fused to the costal part of the antemedial line of forewing.

\section{Redescription}

Antenna of male bipectinate, with long pectinations. Frons yellowish brown. Labial palp long, double eye diameter. Legs yellowish brown, with pale tibial joints. Wingspan 24-30 mm. Forewing yellowish; basal line waved, occasionally costally strongly bulged; antemedial line costally blackish, medially deeply indented; postmedial line costally blackish, medially bulged; central fascia dark yellowish, dorsally reduced, blackish discoidal dot; subterminal line whitish, waved. Hindwing yellowish white, postmedial line very weak.

Male genitalia. - Uncus strongly sclerotized, medially bent, short being less than tegumen height. Tegumen triangular, shorter than vinculum. Saccus shallow, round. Juxta well developed, sclerotized. Anellus lobes digitiform, apically expanded and hairs present. Valva midventrally expanded; costa strongly sclerotized, with median and distal expansions; sacculus sclerotized, with distoventral process. Aedeagus cylindrical, sclerotized; vesica tubular, basally one patch of spinular cornuti present.

Female genitalia. - Anterior apophysis about 1/5 length of posterior apophysis. Antrum simple. Ductus bursae long, strongly sclerotized, basally thick, distally reduced. Corpus bursae ovate, small.

\section{Distribution \\ Europe.}

\section{Remarks}

Pierce (1914) first pointed out that the genitalia of H. firmata are different from Thera s.s. The species was transferred from Thera to Pennithera by Viidalepp (1980), and subsequently it was again moved from Pennithera to Heterothera (Choi 1997). The male and female genitalia of firmata, however, are somewhat different from the typical shape of Heterothera and the cladistic reanalysis of Thera and related genera (Choi unpublished) proposes that the species firmata is separated from Heterothera. Therefore, the generic position of the species is unclear.

\section{Biology}

The species is sometimes bivoltine in England and southern Europe (e.g. Bulgaria), although it is univoltine in northern Europe. Pinus is known as a host plant (Mikkola et al. 1985).

Material examined. - FINLAND: Porvoo, 10 0 , 31.viii.1952, Seppänen; Sibbo, 1 ô, 11.viii.1983, A. Albrecht; Tvärminne Biol. St., 1 ㅇ 13.ix.1951, E. Suomalainen; Helsinki,1 의, 25.viii.1971, A. Albrecht(zMH). - AUSTRIA: Meran, Tirol, 1 , coll. Winter (zмH). - HUNGARY: Sopron, Tacsi drok, 1ิิ, 31.viii.1978, Ronkay; Sopron, Kovas d., 1 ô 1 क , 16.ix.1949, Ambrus; Peszerpuszta, Hungaria cent., 1 , 24.ix.1949, Dr. Issekutz (HNHM). - BULGARIA: Rhodope Mt. Lukovitza motel near Assenovgrad, 450 m, 1 ô, 31.vii.1985, 20ิ, 3.x.1986, S. Beschkov; S.W. Bulg. Kresnensko defile, Station Stara Kresna, 200 m, 10, 17.x.1987, S. Beschkov; Troyanska Stara planina mount. hut Dermenka, 1533 m, 1 \& , 21.ix.1987, S. Beschkov (вNHм).

\section{Thera cyphoschema Prout incertae sedis}

(figs. 40, 41, 56)

Cidaria (Thera) cyphoschema Prout, 1926: 312. Holotype ô, N.E. BURma: Htawgaw, 6000 ft. March 1923, A. E. Swann leg. (вмNH) [examined].

Thera cyphoschema; Prout, 1941: 323.

Cidaria atrinotata Joannis, 1929: 485. Holotype ô, VIETNam: Hoang su phi, Tonkin in Paris Museum (colour transparency in BMNH, [examined]). syn. $\mathbf{n}$.

Cidaria atrinotata reducta Joannis, 1929: 486. syn. n.

\section{Diagnosis}

This species is similar to $H$. mussooriensis in the wing pattern, but differs in the short pectinations of the male antenna and the relatively short and thick uncus, round saccus, unsclerotized costa of valva, the presence of diverticulum of vesica and the absence of cornutus.

\section{Redescription}

Antenna of male bipectinate, with short pectination. Frons reddish and white scales. Labial palp brownish and white, long about twice the eye diameter. Legs 


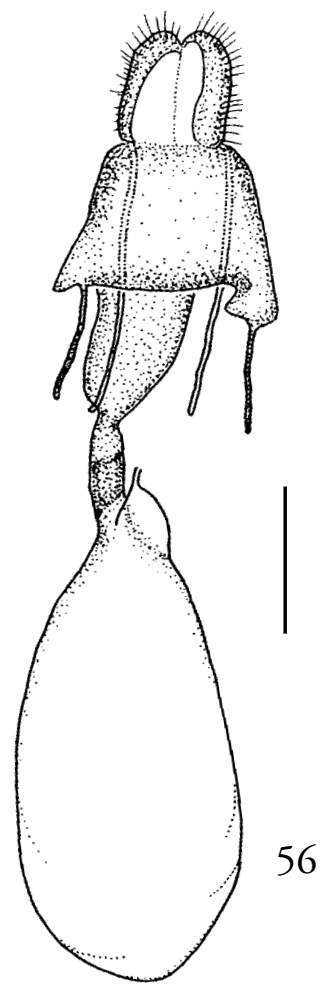

Figs. 56-57.

Female genitalia of Thera s.1. - 56, T. cyphoschema; 57, T. exangulata. Scale bar $=1 \mathrm{~mm}$. brownish and white scales, with white tibial joints. Wingspan $26 \mathrm{~mm}$. Forewing ground colour greyish; basal line blackish, slanted; antemedial line costally blackish, medially indented; postmedial line black, medially bulged; central fascia thin, medially reduced, blackish on veins; dorsum with short blackish line at base. Hindwing whitish, discoidal dot blackish, postmedial line very weak.

Male genitalia. - Uncus thick, relatively short less than half of tegumen, sclerotized. Tegumen domeshaped. Juxta broad, sclerotized; anellus lobe digitiform, medially and apically with long hairs. Saccus round, medially concave. Valva generally membranous; costa membranous, distally slightly projected upward; sacculus triangular, basally sclerotized, with a distal large spinular projection. Aedeagus slender, sclerotized; vesica tubular with one large lateral diverticulum; cornutus absent.

Female genitalia. - Anterior apophysis half of posterior apophysis. Sterigma simple, laterally with thin, sclerotized stripes. Antrum large, funnel-shaped. Ductus bursae with colliculum in middle. Corpus bursae large, subspherical, signum absent.

\section{Distribution}

Burma, S. China, N. Vietnam.

\section{Remarks}

The species is similar to Heterothera in the bipectinate male antenna, the wing pattern and the male genitalia, but it is very different from Heterothera in the female genitalia, particularly the funnel-shaped antrum and the presence of a colliculum. Thus, the inclusion of the species in Heterothera is equivocal.

Additional material examined. - Burma: Paratypes $3 \hat{0}$, Htawgaw, N.E. Burma, 6000 ft. IV- V.1923, A.E. Swann. Htawgaw, N.E. Burma, 6000 ft, 103 9 , IV-V.1923, A.E. Swann. - vietnam: Paratype $1 \hat{\delta}$, Hoang su phi, Tonkin. China: Tseku (Tse-Kou), Prov. Yunnan, 30ิ, 1895, 2 ठิ, 1898, 5 के, 1900, R.P.J. Dubernard (вмNн).

Thera exangulata (Warren) incertae sedis (figs. 42, 43, 57)

Perizoma? exangulata Warren 1909: 127. Holotype + , N. INDIA: Srinagar, Kashmir 7000ft, col[lection]. Ward. 20.VI.[19]04 (вмNн) [examined].

Cidaria (Thera) exangulata Prout 1938: 113.

Thera exangulata; Prout 1941: 323. 


\section{Diagnosis}

The species can be distinguished by the black and medially reduced central fascia and white scalloped subterminal line of forewing. This species is similar to Cidaria deletaria Hampson in the male genitalia (the slender and sclerotized costa), but differs in the wing pattern elements.

\section{Redescription}

Antenna of male filiform. Frons smooth, mixed with ochreous and brownish scales. Labial palp short. Legs dark brownish, with ochreous tarsal joints. Wingspan $32 \mathrm{~mm}$. Forewing basal part dark brownish, slanted; antemedial line costally expanded, slanted; postmedial line medially dentate, bulged; central fascia blackish, costally pale brownish, medially reduced, with long black discoidal dot. Termen brownish, medially paler; subterminal line whitish, scalloping; apical streak brownish. Hindwing whitish; basal part tinged with blackish, with blackish discoidal dot; postmedial line blackish; termen dorsally slightly tinged with black.

Male genitalia. - Uncus about twice as long as tegumen, basally tapering. Tegumen dome-shaped. Saccus round, medially expanded. Juxta broad; anellus lobe long, rod-shaped, dorsally with long hairs. Transtilla sclerotized, thin, round. Valva slender; costa long, slender, distally with long sclerotized hairs; sacculus indistinct. Aedeagus cylindrical, sclerotized, ductus ejaculatorius distally sclerotized; vesica large sac-like, cornutus absent.

Female genitalia. - Papillae anales simple, sclerotized. 8th segment slightly sclerotized. Anterior apophysis about $3 / 5$ length of posterior apophysis. Antrum broad, funnel-shaped. Ductus bursae short, with colliculum. Corpus bursae very large, subovate, posteriorly with many striations; signum a long thread-like process.

\section{Distribution \\ N. India.}

\section{Remarks}

Warren (1909) described the species under Perizoma, but Prout (1938 \& 1941) listed it under Thera.

The wing pattern and especially the female genitalia of the species (funnel-shaped antrum, the presence of colliculum and the thread-like signum) are different from Thera s.l. The male genitalia of exangulata are similar to Cidaria deletaria Hampson, whereas the antrum of female genitalia is similar to $T$. cyphosche$m a$. The systematic position of the species remains unclear.

Additional material examined. - INDIA: Kashmir, $7000 \mathrm{ft}$, 20ิ, 24.vi.; Mussu Hills, 2 추 (BMNH).
Pennithera distractata (Sterneck) comb. n. (figs. 44, 45)

Thera distractata Sterneck, 1928: 152. Holotype + , CHINA: Wassukou (Wassekou), Prov. Sichuan [not examined].

\section{Diagnosis}

The species is similar to $H$. serraria and $H$. serrataria in the wing pattern elements, but it can be distinguished by the short pectinations of male antenna, its wider central fascia and the male genitalia. The well developed bilobed anellus lobe and the medial process at the costa of valva in the male genitalia are characteristic.

\section{Description}

Antenna of male bipectinate, with short pectinations. Frons with white and blackish scales. Labial palp moderate about 1.5 times the eye diameter. Legs with whitish tibial joints. Wingspan $25 \mathrm{~mm}$ in male. Forewing ground colour whitish; basal line blackish, waved; area between basal and antemedial lines tinged with blackish, bar-shaped band; antemedial line waved; postmedial line costally dentate, invaginated, medially slightly bulged; central fascia blackish, relatively constant in width, with black discoidal dot; termen blackish. Hindwing whitish; discoidal dot small blackish, with blackish postmedial line; termen with black, waving subterminal line; fringe black.

Male genitalia. - Uncus long, slender. Tegumen small, dome-shaped. Juxta basally invaginated; anellus lobe bilobed with club-shaped large lobe and densely hairy small lobe, apical part of large lobes with long hairs. Saccus sclerotized, round with medial projection. Valva slender; costa sclerotized, with a medial triangular process. Aedeagus slender, medially bent, distally slightly scobinated; cornutus small process.

Female genitalia. - Unknown.

\section{Distribution}

S.W. China.

\section{Remarks}

The species has never been reported since its original description (Sterneck 1928). The identification of the species is based on the original description and drawing.

The combination with Pennithera is based on the following characters: the relatively smaller tegumen, the triangular process at the middle of the costa and the indistinct sacculus of the male genitalia. The bilobed anellus lobes of the male genitalia are very characteristic.

Material examined. - CHINA: 10 A-tun-tse, (Nord-Yünnan), Obere Hohe, ca. 4500 m, 13.vii.1937, H. Höne (ZFMK). 


\section{ACKNOWLEDGEMENTS}

I thank Dr. F. Rindge (AмNH), Dr. M. Scoble, Miss K. Buckmaster (BMNH), Dr. A. Popov (вNHM), Dr. L. Ronkay (нnнm), Mr. K. Yazaki (Tokyo), Mr. M. Fibiger (Copenhagen), Mr. B. Gustafsson (sNHM), Dr. J. Viidalepp (ZBI), Dr. D. Stüning (ZFMK), and Dr. A. Hausmann (ZSM) for providing the material for this study. Thanks are due to Mr. R. Tyynelä and A. Rusanen for taking the photographs. Dr. Malcolm Scoble (London) and Dr. Kauri Mikkola (Helsinki) made helpful suggestions on an earlier draft. Dr. Jaan Viidalepp (Tartu) helped in many ways to this manuscript. The kind assistance in the editorial process and final publishing of the paper given by Dr. Erik J. van Nieukerken (Leiden) is also appreciated. The study was financially supported by the CIMO, Finland.

\section{REFERENCES}

Bastelberger, M. J., 1909a. Neue Geometriden aus CentralFormosa. - Entomologische Zeitschrift 23: 33-34, 39-40, 77.

Bastelberger, M. J., 1909b. Beiträge zur kenntnis der Geometriden-fauna der Insel Formosa. - Deutsche Entomologische Zeitschrift, Iris 22: 166-182.

Bryk, F., 1942. Zur Kenntnis der Großschmetterlinge der Kurilen. - Deutsche Entomologische Zeitschrift, Iris 55: 3-90.

Bryk, F., 1948. Zur Kenntnis der Großschmetterlinge von Korea. Pars II. - Arkiv för Zoologi 41A: 1-217.

Choi, S.-W., 1997. A phylogenetic study on genera of Cidariini from the Holarctic and the Indo-Australian areas (Lepidoptera: Geometridae, Larentiinae). - Systematic Entomology 22: 287-312.

Curtis, J., 1834. British Entomology: the genera of insects, 2. p. 518. London.

Djakonov, A. M., 1926. Zur kenntnis der Geometriden fauna des Minussinsk Bezirks (Sibirien, Lenissej Gouv.). Jahrbuch des Martjanov'schen Staatsmuseums in Minussinsk (Sibirien) 4(1): 1-78.

Djakonov, A. M., 1955. New and little known Lepidoptera, Geometridae of the fauna of the USSR. - Trudy Zoologischeskogo Instituta Akademii NAUK SSSR 18: 314-319.

Fletcher, D. S., 1961. Geometridae. - In: Lepidoptera der Deutschen Nepal-Expedition 1955, part I. - Veröffentlichungen der Zoologischen Staatsssammlung München 6: 163-178.

Forbes, W. T. M., 1948. Lepidoptera of New York and neighboring states. Part II. - Cornell University Agricultural Experiment Station Memoir 274: 128-175.

Hampson, G. F., 1895. The Fauna of British India including Ceylon and Burma. Vol. 3. p. 379. - Taylor and Francis, London.

Hardwick, D. F., 1950. Preparation of slide mounts of Lepidopterous genitalia. - Canadian Entomlogist 82: 231235.

Herrich-Schäffer, G. A. W., 1847. Systematische Bearbeitung der Schmetterlinge von Europa. 3. Die Spanner. - Regensburg. $183+34$ pp.

Hübner, J., 1822. Sammlung europäischer Schmetterlinge Augsburg, 1-6.
Inoue, H., 1943. New and little known Geometridae from Japan. - Transactions of the Kansai Entomological Society $12(2): 1-25$.

Inoue, H., 1955. New Geometridae from Japan 1. - Kontyu 22: 71-79.

Inoue, H., 1977. Catalogue of the Geometridae of Japan (Lepidoptera). - Bulletin of Faculty of Domestic Sciences, Otsuma Woman's University 13: 227-346.

Inoue, H., 1982. Geometridae. p. 283. In Sugi, S. (ed.), Moths of Japan. - Kodansha, Tokyo.

Inoue, H., 1986. Further new and unrecorded species of the Geometridae from Taiwan with some synonymic notes (Lepidoptera). - Bulletin of Faculty of Domestic Sciences, Otsuma Woman's University 22: 211-267.

Inoue, H., 1992. Geometridae. - In: J. B. Heppner \& H. Inoue (eds.), Lepidoptera of Taiwan, 1 (2): Checklist. Association for tropical Lepidoptera, Gainesville. pp. 111-129.

Jaros, J., K. Spijer, J. Havelka \& K.-T. Park, 1992. Synecological and biogeographical outlines of Lepidoptera communities in North Korea. - Insecta Koreana 9: 78-104

Joannis, J. de, 1929. Lepidopteres Heteroceres du Tonkin. - Annales de la Société Entomologique de France 98: 361-552.

Klots, A.B., 1970. Lepidoptera. - In: S. L. Tuxen (ed.), Taxonomist's glossary of genitalia in insects. pp. 115-130. Munksgaard.

Lederer, J., 1853. Die Spanner. - Verhandlungen der Zoologisch-Botanischen Gesellschaft in Wien 3: 165-270.

Lempke, B. J., 1950. Catalogus der Nederlandse Macrolepidoptera. - Tijdschrift voor Entomologie 92: 113-218.

Lienig, M., 1846. In P. C. Zeller, Anmerkungen zu Lienigs Lepidopterologischer Fauna von Livland und Curland. Isis, Encyclopädische Zeitschrift herausgegeben von Oken. p. 200. Leipzig.

Matsumura, S., 1927. Geometrid-moths collected on Mt. Daisetsu, with descriptions of new species. - Insecta Matsumurana 1: 182-187.

Mikkola, K., I. Jalas \& O. Peltonen, 1985. Suomen Perhoset (Finnish Lepidoptera). Mittarit I (Geometroidea I). - Suomen Perhostutkijain Seura, Tampere. 260 pp. [in Finnish].

Pierce, F. N., 1914. The genitalia of the group Geometridae of the Lepidoptera of the British Islands. - Liverpool. 88 pp., 48 pls.

Prout, L. B., 1914. Geometridae Palearctica. - In A. Seitz (ed.), Die Gross Schmetterlinge der Erde, 4. - Verlag A. Kernen, Stuttgart. pp. 216-220.

Prout, L. B., 1923. New Geometridae in the Tring Museum. - Novitates Zoologicae 30: 191-215.

Prout, L. B., 1926. New Indian Geometridae. - Memoirs of the Department of Agriculture in India 9(8): 247-257.

Prout, L. B., 1938. Geometridae Palearctica. - In: A. Seitz (ed.), Die Gross Schmetterlinge der Erde, 4. Supplement. - Verlag A. Kernen, Stuttgart. pp. 111-115, 245.

Prout, L. B., 1941. Geometridae. In: A. Seitz (ed.), Die Gross Schmetterlinge des Indoaustralischen Faunengebietes, 12. - Verlag A. Kernen, Stuttgart. pp. 323-324.

Rambur, J. P., 1834. Description des plusiers espèces inédites de Lepidoptères nocturnes du centre et du midi de la France. - Annales de la Societé Entomologique de France 3: 379-395.

Sato, R. \& H. Nakajima, 1987. Geometridae. - In S. Sugi (ed.), Larvae of larger moths in Japan. pp. 31-112. - Kodansha, Tokyo. 
Schöyen, W. M., 1875. Fortegnelse over Sommerfugle. Nytt Magasin for Naturvidenskabene 21: 139-146.

Staudinger, O. \& M. Wocke, 1871. Catalog der Lepidopteren des Europaeischen Faunengebiets. - Dresden. 426 pp.

Stephens, J. F., 1829-1831. Illustrations of British Entomology. Haustellata, 3. - Baldwin and Cradock, London. 333 pp.

Sterneck, J., 1928. Die Schmetterlinge der Stötznerschen Ausbeute. Geometridae, Spanner. - Deutsche Entomologische Zeitschrifr, Iris 42: 131-183.

Stichel, H., 1911. Zweiter Beitrag zur nordischen Schmetterlinges fauna und anknüpfende Bemerkungen. - Berliner Entomologische Zeitschrift 56: 33-104.

Strand, E., 1903. Neue norwegische Schmetterlingsformen. Archiv for Mathematik of Naturvidenskab 25(3: 9): 1-24

Viidalepp, J., 1977. A list of the Geometridae (Lepidoptera) of the USSR. Part II. - Entomologiceskoe Obozrenie 16(3): 564-576. [In Russian]

Viidalepp, J., 1980. Geometrid moths of the genus Thera Stph. in the fauna of the USSR (Lepidoptera). - Tartu Riikliku Ülikooli Toimitised 13(516): 54-84. [In Russian with English summary]
Viidalepp, J., 1996. Checklist of the Geometridae (Lepidoptera) of the former U.S.S.R. - Apollo Books, Stenstrup. $111 \mathrm{pp}$.

Warren, W., 1888. On Lepidoptera collected by Major Yerbury in Western India in 1886 and 1887. - Proceedings of the Zoological Society of London 1888: 292-339.

Warren, W., 1909. New species of Thyrididae, Uraniidae, and Geometridae from the Oriental region. - Novitates Zoologicae 16: 123-128.

Wileman, A. E., 1911. New and unrecorded species of Lepidoptera Heterocera from Japan. - Transactions of the Entomological Society of London 1911(2): 189-407.

Yazaki, K., 1994. Geometridae. In Haruta, T (ed.) Moths of Nepal. Part 3. - Tinea 14, Supplement 1: 11-17.

Received: 20 October 1997

Accepted: 13 January 1998 